Archivum, LXXI, 2021, pp. 43-90

\title{
El Gordo, el Flaco y Cervantes: The Bohemian Girl (1843/1936)
}

\author{
Victoria Aranda Arribas \\ UniversidAd de CóRDOBa \\ imberetumbra@gmail.com
}

Recibido: 15/06/2021

Aceptado: 21/07/2021

\section{RESUMEN:}

En 1936 los estudios de Hal Roach estrenaron la comedia The Bohemian Girl. Protagonizada por Stan Laurel y Oliver Hardy -el Gordo y el Flaco-, tomaba como base la ópera homónima (1843) de Michael William Balfe y Alfred Bunn, cuyo libreto se había inspirado a su vez en La gitanilla de Miguel de Cervantes (Novelas ejemplares, 1613). El presente artículo sondea la transformación del relato del complutense desde su publicación hasta su reescritura filmica gracias a la "Factoría de la Risa"; sin orillar tampoco el drama operístico, la fortuna internacional de la historia de Preciosa y sus copiosas decantaciones, cifra y razón de uno de los mitos más influyentes de las letras españolas.

PALABRAS CLAVE: La gitanilla, The Bohemian Girl, Cervantes, Michael William Balfe, Alfred Bunn, Stan Laurel y Oliver Hardy, adaptación cinematográfica, Ópera. 
Stan, Ollie and Cervantes:

The Bohemian Girl (1843/1936)*

\begin{abstract}
:
In 1936, Hal Roach Studies premiered the comedy The Bohemian Girl. Starring Stan Laurel and Oliver Hardy, it was based on a homonymous opera from 1843 by Michael William Balfe and Alfred Bunn, whose libretto was at the same time inspired in La gitanilla by Miguel de Cervantes (Exemplary Novels, 1613). This paper analyses the transformation of the Baroque tale from its publication to the cinematographic rewrite due to "The Lot of Laugh"; without forgetting about the opera, the international success of Preciosa's story and the multiple recreations that, since the $17^{\text {th }}$ Century, contributed to the creation of one of the most influential myths of Spanish literature.
\end{abstract}

KEYWORDS: La Gitanilla, The Bohemian Girl, Cervantes, Michael William Balfe, Alfred Bunn, Stan Laurel y Oliver Hardy, Film Adaptation, Opera.

\title{
1. Un par de cómicos
}

El rodaje de The Bohemian Girl (Un par de gitanos, James W. Horne y Charley Rogers, 1936) no fue precisamente un camino de rosas. Así se lo contaba Oliver Hardy -el Gordo-a su mujer, la también actriz Myrtle Reeves, en carta fechada el 23 de noviembre de 1935: "He trabajado muchísimo. Hay muchas tonterías en esta película... Stan [Laurel] ha estado en cama durante dos semanas y media y Mae Busch durante cuatro semanas. Parece que llevamos así un año" (apud Louvish, 2003, 326)․․

Y no sorprende que el buen talante de Ollie se sublevara frente a las dificultades que atravesó dicho proyecto: además de convalecencias, hubo separaciones, misteriosas muertes, adicciones y eternos desencuentros creativos. Stan Laurel -el Flacose hallaba en pleno proceso de divorcio de su segunda esposa, Virginia Ruth Rogers -con la que, por cierto, volvería a subir al altar seis años más tarde-. Myrtle Reeves intentaba superar su alcoholismo, y Hardy sufría su desintoxicación desde la lejanía.

1 La traducción del libro de Louvish por Idoia Goyeneche (2003) reproduce el característico estilo de Hardy, que solía escribir sin puntuación. Intervengo en la cita para aclarar el pasaje. 
Por si fuera poco, Thelma Todd, que interpretaba a la reina de los gitanos, falleció en sospechosas circunstancias ${ }^{2}$ y fue sustituida por Zeffie Tilbury, cuya avanzada edad obligaría a modificar el guion.

No terminaron aquí los apuros: Hal Roach, promotor del dúo de cómicos hasta 1940, quiso dirigir las escenas dramáticas, pero acabaría centrándose solo en la producción. Detrás de la cámara se pusieron los expertos James W. Horne y Charles Rogers, quienes lidiaban como podían con los roces entre Roach y Stan Laurel, ya una costumbre en sus grabaciones: el intérprete reclamaba mayor poder de decisión e intervenía en los guiones con frecuencia, mientras que Roach no siempre comulgaba con sus humoradas ${ }^{3}$.

A pesar de todo, el filme saldría adelante. Y a nadie le extrañó, porque la fama de las estrellas que abrían el cartel se abrazó con la del argumento en el que se había inspirado la cinta: The Bohemian Girl, un libreto de Alfred Bunn para la ópera de Michael William Balfe, estrenada en el Drury Lane de Londres en 1843, la cual cosechó un triunfo sin precedentes en el mundo anglosajón ${ }^{4}$. Por ejemplo, The Deadborn Independent (Christmas, 1921, 11) informaba en 1921 de que, en medio de una de sus representaciones, una multitud de entre cinco mil y diez mil personas

2 Véase Welkos (2002).

3 A esas alturas, Horne había rodado, entre otras, alguna obra maestra (College, 1927) y dos largos con Laurel y Hardy (Big Bussiness, 1929; Bonnie Scotland, 1935). Por su parte, Rogers demostró su oficio en The Devil's Brother (1933), a partir de la ópera bufa (1830) de Daniel Auber; y en los cortos Me and my Pal (1933) y The Live Ghost (1934).

4 "Para algunos es un melodrama; grand opéra para otros; y no falta quien la considera una ballad-opera. Para nosotros, The Bohemian Girl es una ópera en toda su dimensión. Los diálogos, en su mayor parte, están insertos en fragmentos orquestales a modo de música incidental, compuestos para la obra como teatro que es; en la partitura figura la expresión «melodramatic music»" (Pérez Fernández, 2014, 34). Dentro de la filmografía de Laurel y Hardy, The Bohemian Girl fue la penúltima de una serie de películas basadas en óperas y operetas: Sons of the Desert (William A. Seiter, 1933), The Devil's Brother (Hal Roach y Charles Rogers, 1933) -ya mencionada-, Babes in Toyland (Gus Meins y Charles Rogers, 1934) y Swiss Miss (John G. Blystone, 1938) (Barr, 1974, 88). 
se arremolinó frente a la puerta del auditorio para conseguir un boleto, incluso cuando ya se habían agotado las localidades; y, según The Bismarck Tribune (6), "the story of The Bohemian Girl is probably known to every school child in the [United States]".

Pues bien, aunque a los menos versados en el bel canto el melodrama de Balfe no les resulte familiar, su asunto no dejará indiferente a casi nadie, dado que Bunn tomó como base La gitanilla de Miguel de Cervantes (Novelas ejemplares, 1613) ${ }^{5}$. Es así cómo nuestra literatura se hizo un hueco en la cartelera hollywoodiense el mismo año del estallido de la Guerra Civil -conflicto que no impediría que la comedia de Stan y Ollie se colara entre los títulos más vistos en las salas españolas durante el trienio bélico (1936-1939) ${ }^{6}$. En paralelo, Europa se estremecía ante el avance imparable de los fascismos, un contexto con el que Un par de gitanos también tuvo que bregar:

Es una película que despierta curiosidad [...] sobre la verdadera Europa que caía en la sombra al otro lado del océano, aún lejos de la mirada de Hollywood. El filme fue todo un éxito en Francia, pero se prohibió en Alemania y luego con total rotundidad bajo el régimen de Hitler ${ }^{7}$. No se puede sospechar que los guionistas Charlie Rogers, Jimmy Parrott, Charlie Hall y Stan, sin contar con el productor Roach, tuvieran intenciones políticas a la hora de escoger esta historia en particular. Pero es un hecho en la cronología de la historia que el 15 de septiembre de 1935, unas semanas antes de que comenzara el rodaje en Hollywood, el Reich alemán aprobó las "Leyes de Nuremberg", según las cuales se excluía a todos los ciudadanos de "sangre no alemana", afectando a los judíos y a los gitanos en particular. Esta historia de intolerancia racial, que ocu-

5 Véase González y Medina (2017, 591-592).

6 Cabeza San Deogracias $(2005,122)$ la coloca en quinto lugar, detrás de ¡Centinela, alerta! (Juan Gremillón, 1936), Una noche en la ópera (Sam Wood, 1936), Bajos dos banderas (Frank Lloyd, 1936) y Tiempos modernos (Charles Chaplin, 1936).

7 Puede consultarse una copia del informe de censura en http://www.difarchiv. deutsches-filminstitut.de/filme/f035049.htm (visitado el 06 de marzo de 2021). 
rrió en la Europa central, se vería de una forma diferente en París y Berlín que en Nueva York y Beverly Hills. (Louvish, 2003, 327)

Al margen de los objetivos más o menos panfletarios de sus creadores, es innegable que el contexto histórico repercute decisivamente tanto en la gestación de una película como en su posterior acogida. Y más allá de su vis cómica, las del Gordo y el Flaco, incluyendo sus sketches, no suponen ninguna excepción. Todo lo contrario:

If Chaplin were the comedian of the late Victorian England, then Laurel \& Hardy were the supreme comics of the Great Depression $[\ldots]$. We know they are never going to make it in life-and deep down they know it too. Sometimes it is all too much for them, and they attempt suicide. But something always pulls them through. [...] If the entire canon of Laurel \& Hardy films were a novel then it would constitute a Russian epic of the lower orders, akin to the work of Gogol or Dostoyevsky. (Dutton, 2015, 30-47)

De acuerdo con el trasfondo de la segunda mitad de la década de los treinta, me propongo sondear enseguida el "itinerario transpositivo" de las andanzas de Preciosa: desde la novela cervantina hasta el guion cinematográfico, pasando por el citado libreto de Bunn. Pero este ensayo quedaría incompleto si antes no prestara atención a la fortuna internacional de esta figura cervantina. Mi análisis se levanta sobre los postulados de Serceau (1999), quien entiende la adaptación cinematográfica como "un faisceau de réalité sémiotiques et esthétiques. Réalité plurielle et reversible [...]; un mode de réception et d'interpretation des thèmes et formes littéraires" (9-10). Rastrearé, entonces, "une opération de recontexualisation de la substance thématique qui circule entre la littérature et le cinema" (10).

A su vez, me serviré de la noción de "reescritura", sabedora de que "ha pasado ya a engrosar ese nutrido número de habitantes del purgatorio de los estudios literarios al que van los 
vocablos que mueren de éxito: se ha utilizado en contextos tan dispares y con tantos significados que ha dejado de ser operativo" (Pardo García, 2010, 45).

Sin embargo, también se trata de

[el] más rentable para el estudio de las prácticas adaptativas, especialmente de aquellas que presentan un mayor interés por albergar una opción personal mediante la que el realizador lleva a cabo una auténtica reelaboración del texto de partida proyectando sobre él sus propios intereses ideológicos y estéticos además de las determinaciones derivadas del nuevo contexto en que se inscribe su creación. (Pérez Bowie, 2010, 26)

Ropars $(1990,170)$ defiende con empeño su uso en el dominio fílmico, ya que resuelve la paradoja inherente al término "adaptación" -esto es, el proceso de imitar un texto literario a través de un medio distinto (el cinemático)-, sustituyéndolo y cambiando así el paradigma respecto a los vínculos entre texto y película: “au principe de fidélité, fondé sur la recherche d'équivalence sémiotique, il oppose le point de vue d'un devenir différentiel suivant lequel le film se ferait créateur en s'appropriant, par le geste de récrire, la charge d'invention que suppose l'écriture" (Ropars, 1993, 11).

Y conserva otra ventaja: "reescritura" puede aplicarse tanto a una obra integrada en el mismo medio que sus semillas textuales -"intramedial”, en palabras de Pardo García (2018)- como a la que viaja a otro distinto -“intermedial"-; de ahí que resulte un concepto particularmente operativo a la hora de recorrer un camino con distintas paradas interdisciplinares -la literatura, la ópera, el cine-. Así las cosas, primero pasaré revista a los trasvases teatrales de La gitanilla durante el Barroco, con el objetivo de reconstruir su transmisión hasta llegar al libreto de Bunn. Una vez iluminados sus lazos con la novelita, le tocará el turno a su metamorfosis fílmica en Un par de gitanos, sin dejar caer en saco roto las huellas de Cervantes. 


\section{Entre gitanos anda el juego: la dinastía de Preciosa}

Carmen, Esmeralda, Azucena, Mignon, Fedalma y Morena. Seis nombres que remiten a un mismo arquetipo: la gitana española. Charnon-Deutsch consagró todo un volumen a rastrearlo, cifrando su origen en el Siglo de Oro español:

The first examination of $[\ldots]$ the "imaginary" Spanish Gypsy dates not from the fifteenth-century migrations that resulted in the 1499 Pragmática, however, but from what has been called the Golden Age of Spanish literature, when Spain's ethnic politics produced catastrophic upheavals among Spanish Roma, Moors and the remnants of the Jewish population who had not been expelled by the Catholic monarchs. (Charnon-Deutsch, 2004, 17)

Aunque algún que otro cíngaro asomara la nariz en libros anteriores a Cervantes ${ }^{8}$, fue el autor del Quijote quien prendió la mecha de esta tradición con La gitanilla (1613), pues "el trazo afirmativo y vigoroso con que está captada la figura de Preciosa se impuso inmediatamente a la imaginación de los lectores" (Casalduero, $1969,56)$. Es por eso que "the glamorization of the Gypsy woman" (Charnon-Deutsch, 2004, 19) propició el nacimiento de un modelo femenino que cobrará una entidad literaria propia, separada de su referente de carne y hueso y mucho más célebre que aquel ${ }^{9}$.

8 "Cervantes was not the first to apprise readers of Gypsy difference in manner, dress, speech, and occupations. Several dozen allusions, all very brief, appeared in sixteenth-century Spanish and Portuguese literary texts. These include Celestina (1499), possibly the first mention of Gypsies in Spanish literature, and Farça das Ciganas (A Gypsy Farce, 1521), a comedy by the Portuguese playwright Gil Vicente, featuring the first theatrical appearance of the Gypsy. Other examples following these two early works are Diego de Negueruela's Farsa llamada Ardamisa (A Farce Called Ardamisa), written in the early 1500s; Juan de Timoneda's Comedia llamada Aurelia (A Comedy Called Aurelia; 1564); Mateo Alemán's Guzmán de Alfarache (1599); Lorenzo Palmireno's Estudioso Cortesano (The Studious Courtesan; 1573); and Lope de Rueda's Comedia llamada Medora (A Comedy Called Medora) and Eufemia (1567), to name just a few" (Charnon-Deutsch, 2004, 18).

9 La distancia entre ambos es tal que Charnon-Deutsch (2004) decide aludir a ellos con diferentes voces: "Gypsy", para los gitanos románticos del imaginario 
Pero la idealización con la que ha sobrevivido en la ficción no era tal en La gitanilla, a la que Cervantes agregó una buena dosis de realismo. Por un lado, sus protagonistas, más o menos populares, se desenvuelven en espacios bucólicos, hasta el punto de que "muchos de sus rasgos definidores proceden de los pastores [de] la tradición literaria" (Sevilla Arroyo y Rey Hazas, 1996, XXIV). Tanto es así que Forcione (1982, 187-188) concluiría que "it is tempting to see the Gypsy community as a realm of essential values, a type of "green world», which exposes by contrast the deficiencies of the real world and points toward the ideals that are to be impressed on reality if purification is to occur".

Una dicotomía que saldrá a relucir en el discurso del viejo gitano:

Con estas y con otras leyes y estatutos nos conservamos y vivimos alegres; somos señores de los campos, de los sembrados, de las selvas, de los montes, de las fuentes y de los ríos. Los montes nos ofrecen leña de balde; los árboles, frutas; las viñas, uvas; las huertas, hortaliza; las fuentes, agua; los ríos, peces, y los vedados, caza; sombra, las peñas; aire fresco, las quiebras; y casas, las cuevas. Para nosotros las inclemencias del cielo son oreos, refrigerio las nieves, baños la lluvia, músicas los truenos y hachas los relámpagos. [...]. Por dorados techos y suntuosos palacios estimamos estas barracas y movibles ranchos; por cuadros y países de Flandes, los que nos da la naturaleza en esos levantados riscos y nevadas peñas, tendidos prados y espesos bosques que a cada paso a los ojos se nos muestran. Somos astrólogos rústicos, porque, como casi siempre dormimos al cielo descubierto, a todas horas sabemos las que son del día y las que son de la noche; vemos cómo arrincona y barre la aurora las estrellas del cielo, y cómo ella sale con su compañera el alba, alegrando el aire, enfriando el agua y humedeciendo la tierra; y luego, tras ellas, el sol, dorando cumbres (como dijo el otro poeta)

colectivo; y "Roma", para la etnia real. En el corolario de su estudio falla que "the history of European Roma is a history of social exclusion and physical oppression, while the aesthetic landscape of the Gypsy is one of inclusión and privilege" (239). 
y rizando montes: [...]. En conclusión, somos gente que vivimos por nuestra industria y pico, y sin entremeternos con el antiguo refrán: "Iglesia, o mar, o casa real"; tenemos lo que queremos, pues nos contentamos con lo que tenemos. (Cervantes, 1996, 75-77)

Precisamente la unión entre lo bucólico y lo racial crea el doblez que "ofrece a nuestra mirada una óptica compleja, a la vez que utópica e irónica, de la vida gitana, al mismo tiempo idealizada y realista" (Sevilla Arroyo y Rey Hazas, 1996, XXVII); un atributo que sin duda fomentó el éxito de La gitanilla.

Hablamos de la novela más aplaudida de la colección de 1613. Poetas y dramaturgos pronto se hicieron eco de ella tanto dentro como fuera de nuestras fronteras. Bastará reparar en que, desde 1615 hasta 1691, contamos con una quincena de recreaciones, tanto en prosa como en verso ${ }^{10}$ :

a) La Belle Egyptienne (1615) de Alexandre Hardy, comedia ${ }^{11}$;

10 Charnon-Deutsch (2004) recoge el corpus más ambicioso de todos cuantos he revisado. No obstante, de su elenco habría que excluir cinco títulos: 1) suma una Signorina Zingaretta (1646) de Matteo Grafoni, mientras que data la de Florido De Silvestris en la década de 1630. No obstante, la fechada en 1646 es la comedia de De Silvestris, en la que Matteo Grafoni se redujo al papel de dedicatario; 2) añade una supuesta Verteutschte Spanische Zigeunerin (1656), de Timothoeus Ritzsch y Jacob Cats. Sin embargo, Ritzsch no fue escritor, sino impresor de una versión alemana del poema original de Cats, este sí incluido en mi lista; 3) da por buena la existencia de La gitanilla de Madrid de Pérez de Montalbán, aunque hace oídos sordos al debate sobre su autoría; 4) atribuye a Diego Osorio una Gitanilla de 1657, que no es sino la de Solís, representada ante el rey por la compañía de teatro de Osorio el 10 de abril de 1657 (Serralta, 1987, 144); y 5) incorpora una Gitanilla de James Mabbe de 1640, de la cual no queda rastro alguno. Mabbe fue el primer traductor británico de las Novelas ejemplares, pero su edición -que coincide temporalmente con la adaptación citada por Charnon-Deutsch- se limitaba a trasladar a su lengua un ramillete de solo seis novelas -entre las cuales, por cierto, no está la de Preciosa: Las dos doncellas, La señora Cornelia, El amante liberal, La fuerza de la sangre, La española inglesa y El celoso extremeño-(Garrido Ardila, 2009, 5). Me inclino a pensar que, en tales casos, se trata de "obras-fantasma" fruto de una confusión. Por último, aunque carezco de datos sobre Die Adeligen Komedianten (1644) de Georg Philipp Harsdorffe, tampoco tengo indicios para descartarla.

11 Véase Ruiz Álvarez (1991). 
b) Gipsies Metamorphosed (1620) de Ben Jonson, farsa;

c) The Spanish Gypsie (1623-1624) de Thomas Middleton y William Rowley, tragicomedia que mezcla La gitanilla con La fuerza de la sangre;

d) L'innocente Egyptienne (L'Amphiteatre Sanglant, 1630) de Jean-Pierre Camus, novela;

e) Seltsaam trougeval tuschen en Spaans Edelman en een Heydinne (1637-1643) de Jacob Cats, poema ${ }^{12}$;

f) La Belle Egyptienne (1642) de Monsieur de Sallebray, comediais;

g) La vie de Konstance (1643) de Mattheus Gansneb Tengnagel, teatro;

h) De Spaensche Heiden (1644) de Catharina Verwers Dusart, teatro ${ }^{14}$;

i) La gitanilla de Madrid (1631?) de Antonio Solís, comedia ${ }^{15}$;

j) Signorina zingaretta (1646) de Florido De Silvestris, comedia;

k) Die Adeligen Komedianten (1644) de Georg Philipp Harsdorffer;

12 Es curioso que Cats nunca mencione a Cervantes como su modelo, aludiendo en cambio a un tal "doctor Potzzo" (Vieu-Kuik, 1976, 12-13), trasunto del licenciado Pozo al que el complutense había atribuido la redacción de La gitanilla al final de su relato: "Y de tal manera escribió el famoso licenciado Pozo, que en sus versos durará la fama de la Preciosa mientras los siglos duraren" (Cervantes, 1996, 113). Véase Koopman.

13 Véase Dalla Valle.

14 Las obras firmadas por Gansneb Tengnagel y Verwers Dusartdos se inspiraron en el poema de Jacob Cats (Gaskell, 1982, 263).

15 Compilada en la Parte treinta y siete de comedias nuevas escritas por los mejores ingenios de España (Madrid, Melchor Alegre / Domingo Palacio y Villegas, 1671). Existe una segunda redacción, titulada La gitanilla, cuya autoría se ha atribuido tanto a Solís como a Juan Pérez de Montalbán. Según Vaiopoulos (2010, 138-139), “los cambios de las dramatis personae crean el típico reparto de la comedia de enredo y, al mismo tiempo, producen los mecanismos de reconstrucción de la acción [...]. Los puntos de contacto entre los textos son limitados y las escisiones eliminan la mayor parte del material diegético de la novela, [lo cual permite] reducir el tiempo a un solo día y el espacio a una ciudad [Toledo]". Según explica Charnon-Deutsch (2004, 41), "among Spanish adaptations, [this] is the most famous"; de hecho, la Esmeralda de Victor Hugo "may have been strongly influenced by Antonio de Solís y Rivadeneira's La gitanilla de Madrid" (55). 
1) Les fourberies de Scapin (1671) de Jean-Baptiste Molière;

m) Histoire du baron de Merargues et de la belle Egyptienne (Histoire du temps, ou Journal galant, 1685) de Claude Vanel, novela;

n) La finta zingara (1651) de Reinaldo Sgambati, comedia;

n) Con le borasche in porto, overo la zingaretta di Madrid (1691) de Carlo Celano, comedia ${ }^{16}$.

Durante el siglo XVIII, la formidable gitana siguió muy de moda, alcanzando nuevas cotas de popularidad a lo largo del siguiente. Los franceses -fascinados y horrorizados a partes iguales por la música, los bailes, las ropas y las costumbres de estos calés- fantasearon con una suerte de "gitanería hispana", independiente de la europea, cuyos orígenes situaron en el norte de África ${ }^{17}$. A través de los libros de viajes, los turistas galos evocaron sus impresiones sobre un país al que ya acudían con la imaginación más que exaltada. De ahí que su periplo por nuestras tierras -sobre todo por las sureñas- se desenvolvieran en el marco de un onírico exotismo, igual que sus crónicas.

Valga como ejemplo el siguiente pasaje de Théophile Gautier $(2008,188)$ :

Vamos a visitar el Sacro Monte, montaña donde se hallan las cuevas de los gitanos, que en Granada son numerosísimos. [...] La entrada a estas cavernas suelen estar deslumbrantemente blanqueadas. En el interior de ellas se aloja una familia salvaje; bullen los chicos con la piel más oscura que el tabaco y allí juegan desnudos, sin distinción de sexos, dentro o en el umbral, revolcándose en el polvo entre risas y gritos agudos. Guardan mil recetas para

16 Véase Vaiopoulos (2003, 36-37).

17 "To draw a racial distinction between Gypsy and non-Gypsy Andalusians but still apply popular concepts regarding climactic determinism, the anonymous historian J. M. (generally thought to be Baron François Jacques Jaubert de Passa, who traveled frequently to Spain to study irrigation systems) speculated in 1832 that because of their darker skin color Spanish Gypsies originated in Northern Africa, specifically in the Yemen desert and regions bordering on Egypt" (Charnon-Deutsch, 2004, 53). 
excitar y dar animación a las más viejas caballerías; un gitano habría hecho galopar a Rocinante y dar cabriolas al Rucio de Sancho [...]. Las gitanas venden amuletos, dicen la buenaventura y practican todas esas extrañas industrias que son comunes a las mujeres de su raza [...]. Su tez curtida hace resaltar la limpidez de sus ojos orientales, cuyo ardor está templado por un no sé qué de tristeza misteriosa. Algo de nostalgia de la patria ausente y de su grandeza desaparecida. La boca, de labios muy gruesos, asemeja a las bocas africanas. La frente es estrecha y la nariz tiene la forma habitual de los zíngaros de Valaquia y Bohemia, $\mathrm{y}$, en general de todos los hijos de este extremeño pueblo que, procedentes de Egipto, atravesó enigmáticamente la Edad Media, sin que hasta ahora se hayan conseguido fijar su verdadera filiación. Las gitanas tienen un porte majestuoso y sus bustos están perfectamente colocados sobre las caderas, a pesar de sus andrajos, su suciedad y su miseria. Parecen tener conciencia de la pureza de su raza.

Nótese cómo el espíritu rebelde de los románticos corporizó sus propias ambiciones en los cíngaros andaluces, ajenos a las normas de la sociedad, y siempre en comunión con la naturaleza: "Andalusia was constructed as a dream world where time could be slowed, life savored to its fullest, and the disturbances and hypocrisy of the modern, "civilized» world of large European capitals avoided" (Charnon-Deutsch, 2004, 59). En paralelo, surgirían nuevas hijas de Preciosa que aquilataron el mito, transformándolo. Destacan entre ellas la Esmeralda de Victor Hugo (Nuestra Señora de París, 1831) y la Carmen de Mérimée (1845) -y después de Bizet (1875)-, sin menospreciar a la Moréna de George Sand (La filleule, 1853).

Nada extraña que tan fecunda tradición perviviera hasta el invento del cinematógrafo: en Francia, André Hugon -realizador de origen argelino- adaptó la novela de Cervantes en $1923^{18}$. Su

18 Es notable la afición que sentía Hugon (1886-1960) hacia la cultura peninsular y, en concreto, por Cervantes, pues no solo rodó La gitanilla, sino que también se propuso adaptar un Don Quijote que, finalmente, no llevó a término (Seguin, 2015, 259). 
película, hoy perdida, la protagonizaron Ginette Maddie, Jaime Devesa y José Durany. Apenas una década antes, se sabe -o cree saberse- de otra versión rodada por Louis Feuillade en 1914: $\mathrm{La}$ gitanella. No obstante, Seguin $(2015,250-253)$ ha argüido que se trata de una superchería fruto de la confusión entre: a) el título español de otra de las cintas de Feuillade: L'enfant de la roulotte (1914), que coincidía con el de la primera de las Novelas Ejemplares (aunque sus tramas no tengan nada que ver); $b$ ) un guion anónimo -jamás rodado- de la casa Gaumont que trasladaba, esta vez sí, La gitanilla ${ }^{19}$; y c) un largo del mismo Feuillade, de ambiente gitano, que en el país vecino atendió por La gitanella (1914), mientras que en el nuestro se estrenaría como Pepita la Gitana. Sea como fuere, resulta evidente que dicho tópico estaba vivo en la sociedad gala de las postrimerías del siglo XIX y los albores del XX.

España tomó conciencia de la baza turística que le brindaba la fantasía de los viajeros europeos, haciendo de la equivalencia entre lo hispánico y lo gitano "one of the essential factors in the configuration of the modern image of the country" (Jesús Torrecilla apud Charnon-Deutsch, 2004, 132). De este modo, el relato cervantino también incursionaría en nuestro cine mudo gracias a La gitanilla (Adriá Gual, 1914) ${ }^{20}$, La gitana blanca (Ricardo de Baños, $1919 / 1923)^{21}$ y, ya en el sonoro, La gitanilla (Fernando

19 Puede leerse una transcripción del libreto en Seguin (2015, 271-277).

20 Primera versión cinematográfica de una novela ejemplar y tercer proyecto de la Barcinógrafo, productora de Gual. García Fernández $(2002,75)$ precisa que "estaba destinada a [inaugurar] un ciclo sobre las [...] Ejemplares, pero las malas críticas y los pésimos resultados en taquilla hicieron que [su plan] se viera frustrado". El guion corrió a cargo del periodista Rafael Marquina (1887-1960) y la protagonizaron Elisa Beltrán y Gerardo Peña (Seguin, 2015, 256).

21 De Baños estrenó en 1919 Arlequines de seda y oro, dividida en tres partes: El nido desecho, La semilla del fenómeno y La voz de la sangre. La ligazón con el texto cervantino radica en su íncipit: un rico conde, presa de los celos, entrega sus dos hijos a un grupo de gitanos para vengarse de su mujer. Estos internarán en un hospicio al niño -que acabará triunfando como torero-, mientras que la pequeña pronto hará suyas las costumbres calés, convirtiéndose en la célebre cantante Raquel (Raquel Meller). Pasados varios años, los hermanos se encuentran y, sin reconocerse, se ena- 
Delgado, 1940)22. Este gusto de la cartelera española por todo lo romaní tampoco se disipó a medida que avanzaba la centuria; doce pruebas de ello son Morena clara (Florián Rey, 1936), Martingala (Fernando Mignoni, 1940), Canelita en rama (Eduardo García Maroto, 1943), Embrujo (Carlos Serrano del Osma, 1947), Morena clara (Luis Lucía, 1954), Los Tarantos (Francisco Rovira Beleta, 1963), El amor brujo (Carlos Saura, 1986), Calé (Carlos Serrano, 1987), Yo soy esa (Luis Sanz, 1991), La Lola se va a los puertos (Josefina Molina, 1992), Alma gitana (Chus Gutiérrez, 1995) o La niña de tus ojos (Fernando Trueba, 1998) ${ }^{23}$.

\section{De la novela al libreto: The Bohemian Girl (1843)}

Preciosa también se perpetuó en el mundo anglófono del Romanticismo. Tengamos en cuenta que el filólogo y viajero británico George Borrow

moran perdidamente. Hay, sin embargo, una fuerza invisible que les niega su idilio. Gracias a una marca de nacimiento, su padre, admirador de ambos artistas, los identifica y les desvela la verdad acerca de su origen. Debido al éxito obtenido por la actuación de Raquel Meller, en el que fue su debut en la pantalla, en 1923 Royal Films decidió montar una versión más breve que enfatizara el protagonismo de la actriz: La gitana blanca. Véase Aranda Arribas.

22 Última versión fílmica hasta la fecha. Tampoco en este caso ha sobrevivido ninguna copia. Probablemente se trate de la cinta con mayor repercusión en su día, dado que gozó de un presupuesto de veras holgado: 1.226.595 pesetas (Cabero, 1949, 438). Protagonizada por Estrellita Castro y Juan de Orduña, el guion de Antonio Guzmán Merino "seguía literalmente la acción de la novela según el argumento publicado en la colección La Novela Semanal Cinematográfica en mayo de 1940" (Nieto Jiménez, 2012, 179).

23 Dicha imagen se acentuó durante el Franquismo, ya que "for all their desire to sell Spain's glorious castizo, that is, its pure-blooded, imperial heritage, the writers of the Franco era knew that what really sold in the world-tourism market in which Spain was eager to participate was Andalusianism, and a defining element of it, its «salt and pepper», was its Gypsy heritage. The promotion of Andalusianism with its strong nostalgia for a Romanticized, mysterious past helped to construct a collective national identity while camouflaging unequal relations of power and repressive social structures" (Charnon Deutsch, 2004, 210). Huelga explicar que este ensayo aborda el cine sobre gitanos (reales o ideales), pero no el rodado por gitanos, categoría en la que brillan con luz propia Tony Gatliff (Corre, gitano, 1982; Gadjo dilo, 1997; Vengo, 2000; Korkoro, 2010) y Emir Kusturica (Tiempo de gitanos, 1988; Underground, 1995; Gato negro, gato blanco, 1998; On the Milky Road, 2016). 
rendered both British and Spanish Gypsies so as to reflect the popular mid-century's conception of the Gypsy as the embodiment of romance, adventure, passion, violence, and unfathomable codes of conduct, something that carried over to representations of Gypsies in popular British literature and theater. (Charnon-Deutsch, 2004, 12)

Casi dos siglos después del par de versiones de Ben Jonson y de Rowley y Middleton, el norteamericano Henry Wadsworth Longfellow estrenó The Spanish Student (1843), basada no solo en La gitanilla de Cervantes, sino también en varios de sus traslados teatrales ${ }^{24}$. Y ese mismo año Alfred Bunn y Michael William Balfe presentaban la que se convertiría en la ópera inglesa más famosa de la historia: The Bohemian Girl ${ }^{25}$. Como explica Hancock (2002, s.p.), nos hallamos ante

a work of popular entertainment that almost everyone knew around the turn of the 19th and 20th centuries and almost no one knows today. For more than 70 years, beginning in 1843, it was the most widely performed opera in English in the English-speaking world, at a time when opera was one of the most popular forms of entertainment and more than 200 opera companies toured the United States.

24 Véase Piñeiro Gil (1994).

25 De acuerdo con Monrós-Gaspar $(2017,275)$, tras el éxito de la ópera de Balfe, en los años sesenta surgen "recreaciones populares que incluirán diversas revisiones burlescas. Por ejemplo, Arline; or, the Fortunes and Vicissitudes of a Bohemian Girl (1851) de William Brough, [en collera] con su hermano Robert; The Gipsy Maid (1861) de William Brough; The Bohemian Girl (1861, autor desconocido), Arline the Lost Child; or, The Pole, the Policeman and the Polar Bear (1864) de Henry Bellingham (a cuatro manos con William Best); The Merry Zingara (1868) de W. S. Gilbert y The Bohemian G'yrul (1877) de Henry James Byron. En la citada década de los sesenta también brilló el drama The Gitanilla; or, the Children of the Zincali (1860) de J. Crawford Wilson". Resulta significativo que el origen de las dos óperas más célebres de Francia (Carmen) y Reino Unido (The Bohemian Girl) se remonte precisamente a $L a$ gitanilla. Este dato vuelve a poner sobre el tapete el magnetismo del tema en el extranjero. Añadiré, por fin, la frecuencia de las "fantasías españolas" en el repertorio operístico del XIX: El barbero de Sevilla (1815) de Rossini; y Ernani (1844), Il trovatore (1852) o La forza del destino (1862), las tres de Verdi. 
Disfrutó de más de cien representaciones en Londres y "los temas principales calaron de tal manera que el público pudo memorizarlos y entonarlos por la calle" (Pérez Fernández, 2017, 22). En 1844 se representó en Dublín, Filadelfia y Nueva York, y a lo largo del siglo XIX se fue programando en las principales capitales del mundo ${ }^{26}$.

El libreto hacía suyo el argumento de La gitanilla, pero lo interpolaba con la trama del ballet La Gypsy (1839), de Jules-Henri Vernoy de Saint-Georges y Joseph Mazilier, y con la novela Tadeo de Varsovia (1803) de Jane Porter. El primero también se cimentaba sobre el relato de Cervantes, pues cuenta la peripecia de una niña escocesa raptada por un grupo de gitanos que, cuando crece, se ve envuelta en un desastrado triángulo (Craine y Mackrell, $2010,204)$. En cuanto a la segunda, se trata de un texto de notable éxito durante el XIX, habida cuenta de que allanó el camino para el adviento de la novela histórica ${ }^{27}$. Bunn y Balfe reciclaron el personaje central, Thaddeus -cuyo nombre conservarían-, nieto de un ilustre conde polaco que se exilia en Inglaterra tras la invasión rusa.

Me propongo ahora mostrar las diferencias argumentales entre la novela cervantina y el libreto de Bunn. He aquí un breve

26 En 1845 se anunció en Madrid; en 1846, en Hamburgo, Viena y Sydney; y luego en Brünn y Praga, ya en 1847. Después recalaría en Frankfurt y Estocolmo (1849); Múnich y Berlín (1850); Trieste, Brescia, Verona, Bolonia y Zúrich (1854); Amsterdam (1855); Basilea (1861); Rouen (1862); Lieja (1863); Gotemburgo (1865), París (1868); Zagreb (1872); Toronto (1874); Nueva Orleans (1876); Chemnitz (1879); México (1884); Teplitz (1886); Ciudad del Cabo (1887); Darmstadt (1888); Coburgo (1892); y Posen (1902), tampoco faltó a la cita con San Petersburgo (c. 1855 y 1962). Fue traducida al alemán, al italiano, al francés, al sueco, al croata y al ruso (Pérez Fernández, 2017, 175-176).

27 Se reeditó al menos ochenta y tres veces, incluyendo paráfrasis al francés y al alemán (Looser, 2008, 157). Por otro lado, "Porter's significance in the development of the historical novel and national tale has been seriously undervalued, and that the first volume of Thaddeus of Warsaw is a particularly fruitful place to see literary history in transition. Porter [...] crafted and pioneered many of the narrative tools most commonly associated with both the national tale and the historical novel. Scholars therefore should consider her significance not only for Scott but also for Morgan, de Stael, Edgeworth, and Charles Robert Maturin" (McLean, 2007, 99). 
resumen de la primera: una vieja gitana rapta a la hija de los corregidores de Murcia. Preciosa -este será su nombre durante la mayor parte del relato- crece ajena a su verdadero origen, aprendiendo a desenvolverse dentro del clan. A los quince años, su belleza, discreción y gracia al bailar atraerán las miradas de propios y extraños, pues, más allá de haberse criado entre cíngaros, despunta por su espíritu virtuoso. En Madrid, don Juan de Cárcamo, un noble galán, se prenda de ella y no tarda en proponerle matrimonio. Preciosa aceptará con la condición de que su pretendiente conviva junto a los suyos durante al menos un par de años. Rebautizado como Andrés, el caballero se adapta a su nueva vida, pero se abstiene de delinquir.

Los conflictos entre ambos tienen dos nombres propios: Clemente y Juana Carducha. El primero es un paje-poeta que en Madrid regalaba con sonetos a Preciosa; su visita al aduar despierta los celos de Andrés, hasta que se descubre que Clemente es un huido de la justicia y no lo mueve ninguna aspiración amorosa. Por su parte, Carducha, moza de una venta cercana a Murcia, pierde la cabeza por Andrés. Al ser rechazada, meterá algunas de sus joyas entre los bártulos del mancebo, que será denunciado a las autoridades y condenado a morir en la horca. Preciosa queda devastada por la noticia. Su abuela adoptiva, incapaz de verla sufrir, la llevará ante los corregidores, su auténtica familia. Tras confesar el rapto, la anciana revela su verdadero nombre: Constanza de Acevedo y Meneses. Los padres lloran entonces de alegría y abrazan a la "hija perdida y hallada", que les suplica la liberación de su caballero, con el que contraerá matrimonio.

La ópera sitúa la acción en la ciudad de Presburgo (actual Bratislava), gobernada por el conde Arnheim, que tras la muerte de su esposa reside en un castillo junto a su hija Arline. El primer acto comienza con un día de caza en el que la pequeña sale a pasear junto a su niñera. Enseguida conoceremos a Thaddeus, joven polaco que huye de los soldados austríacos. Cerca de los dominios de Arnheim, se topa con un grupo de gitanos. Devilshoof, jefe de este clan, lo acepta entre los suyos y le proporciona ropa 
para ocultar su identidad. De pronto suenan voces de alarma: Arline es víctima del ataque de un ciervo y Thaddeus la salva de una muerte segura. En agradecimiento por su heroicidad, el conde invita a Thaddeus a un banquete, al que este acudirá acompañado de Devilshoof. Cuando Arnheim propone un brindis por el emperador, los cíngaros se niegan, dando lugar a una disputa que acaba con Devilshoof en el calabozo de la fortaleza. El prisionero logra huir y, como venganza, se lleva consigo a Arline.

La niña crece sin recordar su procedencia y Thaddeus la cuida como si él la hubiera engendrado. Pronto surgirá el amor entre ambos y acabarán prometiéndose. Su relación enoja a la reina de los gitanos, que, para más inri, bebe los vientos por Thaddeus. Pasarán doce años desde el rapto de Arline hasta su postrero regreso a Presburgo. Es allí donde los calés atracan a Florestein, primo de la protagonista. Devilshoof le arrebata un valioso medallón, obsequio del emperador, que la jerarca del campamento le requisará so pretexto de devolvérsela a su dueño. Pero su verdadero plan es cedérselo a Arline con pícara amabilidad para que la acusen del robo. Dicho y hecho: en una feria, Florestein descubre la alhaja en el cuello de la dueña y se la lleva arrestada al castillo de su tío, a la sazón padre de Arline. Allí, el conde distingue una cicatriz en el brazo de la muchacha: la misma que luego estima como secuela del ataque del ciervo. Se activa así la anagnórisis y Arline recobra su identidad. Después, confesará a su progenitor su deseo de casarse con Thaddeus, aspiración que el conde Arnheim rechaza hasta que el aristócrata polaco publica su linaje.

Al leer el libreto, lo primero que salta a la vista es el desplazamiento del protagonismo femenino en favor de Thaddeus. Este personaje se configura como un sosias del Juan/Andrés cervantino: ambos son dos nobles que se hacen pasar por cíngaros y se enamoran de la ilustre gitana. No obstante, también las antinomias tienen su importancia: mientras que la incursión de Juan entre los calés es del todo voluntaria y se deriva de su atracción por Preciosa, para Thaddeus se trata de la única escapatoria posible. Tal cir- 
cunstancia emparienta al polaco con Clemente, pues, a diferencia de Juan, este sí se refugia en el aduar para sortear a la justicia.

Asimismo, la Juana Carducha novelesca se convertirá en reina de los gitanos: lo cual no evita que ambas -también la operística- sean despechadas por un hombre que prefiere a la protagonista; y tanto la una como la otra detonarán el conflicto por medio de un robo fingido. Pero si en el relato la ventera buscaba vengarse de Juan ocultando en sus alforjas las joyas, su correlato musical pondrá sus miras en Arline.

Otro punto en común atañe al motivo de la agnición: Preciosa es reconocida por una mancha "debajo de la teta izquierda" y por "los dos dedos últimos del pie derecho, [que] se trababan el uno con el otro por medio de un poquito de carne" (Cervantes, 1996, 106). Y no se olvide que Arnheim identifica a Arline gracias a la cicatriz, secuela del ataque del ciervo. En realidad, la trama de una muchacha de clase baja que acaba descubriendo su origen ilustre hunde sus raíces "en narraciones folklóricas y mitológicas" que Cervantes tradujo a modo de cuento: "una forma [...] elemental [bajo] directrices temáticas y estructurales tales como el happy end, la amplificación argumental, la triplicación o el desenlace matrimonial obligatorio" (Ivanovici, 2001, 214-217) ${ }^{28}$.

En cuanto a las protagonistas, si la cariñosa familiaridad que unía a Preciosa con su abuela adoptiva sobrevivía a la confesión del rapto en el relato, el único lazo de la gitanilla con su entorno será Thaddeus -figura parental y amante a un mismo tiempo-, quien, para colmo, no es gitano de verdad. Luego valdrá afirmar que Arline no se siente a gusto entre los cíngaros. No en balde, cuando su reina la reprende por haberse fijado en Thaddeus, ella le espeta: "I possess his heart, and will yield the possession to no one. He is the savior of my life, and the only friend I have in all the tribe: he has shown how much he loves me" (Bunn, $2017,110)$. Otra diferencia de fuste respecto a la novela reside en la anulación del misterio sobre el origen de Preciosa. Cervantes

28 Son imprescindibles los trabajos de Pierre Darnis sobre el sustrato folklórico en las Novelas ejemplares (2007, 2010, 2013, 2014 y 2015). 
abría la historia in medias res y, aunque deslizó algunas pistas que sugieren un posible secuestro ${ }^{29}$, los hechos se desarrollan sin que sepamos quiénes son los padres de su protagonista:

Parece que los gitanos y gitanas solamente nacieron en el mundo para ser ladrones: nacen de padres ladrones, críanse con ladrones, estudian para ladrones y, finalmente, salen con ser ladrones corrientes y molientes a todo ruedo; y la gana del hurtar y el hurtar son en ellos como accidentes inseparables, que no se quitan sino con la muerte. Una, pues, desta nación, gitana vieja, que podía ser jubilada en la ciencia de Caco, crio una muchacha en nombre de nieta suya, a quien puso nombre Preciosa, y a quien enseñó todas sus gitanerías y modos de embelecos y trazas de hurtar. (Cervantes, 1996, 31-32)

No se ignore que, debido al "antigitanismo" que imperaba en el Madrid de Felipe III -desde 1609 a 1613 se sancionaron órdenes de expulsión-, esta novelita hubo de asombrar a los lectores de la época, "que esperarían cualquier cosa menos una idealización de los gitanos" (Sevilla Arroyo y Rey Hazas, 1996, XXIXXXX). Cervantes reaccionaba así contra las prácticas racistas de su tiempo. Además,

que Preciosa sea gitana exige una reflexión sobre el alcance de esa elección literaria, puesto que no deja de ser un hecho hasta cierto punto insólito y no exento de una profunda originalidad. Los gitanos están ausentes de tradición literaria y, además, el tratamiento literario de una minoría social incidía sobre la definición de las ideas de Cervantes al respecto; en fin, cabe interrogarse sobre el uso del tema en el decurso del relato. (García López, 2013, 830)

29 Los nobles que admiran los bailes de Preciosa exclaman: “¡Lástima es que esta mozuela sea gitana! En verdad, en verdad, que merecía ser hija de un gran señor" (Cervantes, 1996, 36); y ella confesará, casi a renglón seguido, que, "aunque soy gitana pobre y humildemente nacida, tengo un cierto espiritillo fantástico acá dentro, que a grandes cosas me lleva" (57). 
Bunn, en cambio, subraya la feliz infancia de Arline con su padre y el posterior rapto a manos de Devilshoof. Por tanto, el espectador sabe desde el principio que la muchacha no es discreta "a pesar de ser gitana" -como sugiere Cervantes-, sino justamente porque no lo es. De hecho, la propia Arline intuye que no pertenece a ese mundo; una sospecha de la que se desprende la composición más popular de The Bohemian Girl, el aria I Dreamt I Dwelt in Marble Halls ${ }^{30}$ :

I dreamt that I dwelt in marble halls, with vassals and serfs at my side, and of all who assembled within those walls, that I was the hope and the pride.

I had riches too great to count, could boast of high ancestral name; but I also dreamt, which pleased me most that you loved me still the same.

I dreamt that suitors sought my hand, that knights upon bended knee, and with vows no maiden heart could withstand, they pleg'd their faith to me.

And I dreamt that one of that noble host came forth my hand to claim; but I also dreamt, which charm'd me most, that you love'd me still the same. (Bunn, 2017, 104)

Lejos queda ya aquel orgullo calé de Preciosa, la cual rechazaba la proposición de un teniente para llevarla ante sus majestades: "Querranme para truhana -respondió Preciosa-, y yo no lo sabré ser, y todo irá perdido. Si me quisiesen para discreta, aún llevarme hían, pero en algunos palacios más medran los truhanes que los discretos. Yo me hallo bien con ser gitana y pobre, y corra la suerte por donde el cielo quisiere" (Cervantes, 1996, 54). 
No obstante, otros rasgos de Arline son deudores de su referente cervantino: aunque no se lucra bailando -como Preciosa-, sí que dice la buenaventura. Al llegar a la feria donde la arrestarán, reclama de esta guisa la atención de la multitud:

Sir knight and lady, listen!

(to a lady) That bright eye seems to glisten

as if his trusted tale

did o'er thy sense prevail!

(to another, pointing to her heart)

Pretty maiden, pray, take care,

love is marking havoc there!

(to a third, pointing to a ring on her finger)

This token, which from love you borrow,

the prelude is of many sorrow!

There are those have liv'd to know,

the gipsy's words are true. (Bunn, 2017, 122)

Esta escena evoca aquella en que Preciosa vaticinaba el futuro de la mujer del teniente en un largo romance no exento de burla $^{31}$. Copio solo un fragmento:

31 Márquez Villanueva dedicó un fino estudio al que "cabría calificar como enfant terrible de los poemas cervantinos" $(1985,743)$ y "una de las claves fundamentales para el lector inteligente de La gitanilla" (745). También repararon en él Rodríguez-Luis $(1980,114)$ y Forcione $(1982,138)$ : “Here we discover a marriage in which both partners exhibit a good deal of violence and lust, frequently scold and beat one another, and appear to be yoked until death in a conjugal relationship plagued by tyranny, fear, jealousy and adultery". Finalmente, Torres $(2018,147)$ apunta que "la desenvoltura de Preciosa se manifiesta ante todo en la poesía, su honestidad tantas veces proclamada le da una libertad extraordinaria para denunciar la deshonestidad que encarnan el teniente y su mujer doña Clara". En general, los versos de $L a$ gitanilla se antojan un elemento clave, habida cuenta de que "Cervantes se muestra [...] como un poeta de amplio y variado registro que ha convertido la primera de sus Novelas ejemplares en campo abonado para la reflexión sobre la poesía, convertida también en tema central de aquella y, al tiempo, en un magnífico ejemplo de su quehacer poético" (Montero Reguero, 2013, 36). 
Hermosita, hermosita, la de las manos de plata, más te quiere tu marido que el Rey de las Alpujarras.

Eres paloma sin hiel, pero a veces eres brava como leona de Orán, o como tigre de Ocaña.

Pero en un tras, en un tris, el enojo se te pasa, y quedas como alfinique, o como cordera mansa.

Riñes mucho y comes poco: algo celosita andas; que es juguetón el tiniente, y quiere arrimar la vara. (Cervantes, 1996, 51)

Preciosa se rebela contra la jactancia de los nobles payos, a los cuales responde sin complejos a la menor ocasión, denunciando la hipocresía de los que se fingen honestos para defender su orgullosa virtud. Cuando los tenientes ponen excusas a la hora de pagarle por sus servicios, les ataja con ironía:

Antes, si no me dan nada [...] nunca más volveré acá. Mas sí volveré, a servir a tan principales señores, pero trairé tragado que no me han de dar nada, y ahorrareme la fatiga del esperallo. Coheche vuesa merced, señor tiniente; coheche y tendrá dineros, y no haga usos nuevos, que morirá de hambre. Mire, señora: por ahí he oído decir (y, aunque moza, entiendo que no son buenos dichos) que de los oficios se ha de sacar dineros para pagar las condenaciones de las residencias y para pretender otros cargos. (Cervantes, 1996, 53)

Aunque no de forma tan cruda, también Arline sacará las uñas cuando Florestein intenta sobrepasarse: 
Florestein. Fair creature, your manner has enchanted me, and I would take a lesson from you.

ArLine. In politeness, sir? By all means! To begin then, whenever you address a lady, take your hat off.

FLORESTEIN. Very smart (with a titter), 'pun my word, very smart. Your naïvité only increases the feelings of admiration and devotion which a too susceptible heart...

ArLine. (Bursting out laughing) Ha ha ha!

Florestein. Your indifference will drive me to despair.

ArLine. Will it really?

Florestein. Do not mock me, but pity my too susceptible nature, and let me print one kiss upon... (Here Arline gives him a violent slap on the face). (Bunn, 2017, 124)

Por último, aunque al principio reniega de su crianza gitana y sueña con desfilar por salones de mármol, ya de vuelta al castillo paterno, mira con nostalgia sus antiguas ropas:

I am once more left to my thoughts, and all the deep regrets which accompany them; nothing can drive the recollection of Thaddeus from my mind, and the lonely life I led was to me far happier than the constrained one I now pass; and the graceful dress of the gipsy fit becomes me more than all this gaudy apparel of nobility. [...] The sight of this recalls the memory of happy days, and of him who made them happy. (Bunn, 2017, 142)

Pero ni siquiera ahora se afirma con rotundidad su amor por aquella etapa: no queda claro si añora de veras el aduar o solo la compañía de Thaddeus. Nótese que, cuando el polaco regresa a su lado y su padre admite el matrimonio, ya no hay lugar para la nostalgia:

Oh, what a full delight

thro' my bosom thrills, and a wilder glow 
in my heart instills!

Bills unfelt before,

hope without alloy

speak with raptur'd tone

of my heart the joy! Ah! (Bunn, 2017, 160)

Si bien la Preciosa de Cervantes no se disgustó al descubrirse noble, "tan pronto como se [revela] su identidad [...] deja casi por completo de hablar por sí misma, siendo el narrador quien nos informa de lo que responde" (Rodríguez-Luis, 1980, 137). Y cabe leer este mutismo final como muestra de la anulación de su carácter una vez separada de los gitanos ${ }^{32}$.

Pero si en la novela era Juan el dispuesto a renunciar a su linaje por amor, aquí será Arline la que favorezca a Thaddeus, haciendo caso omiso de su cuna. Opino, pues, que la protagonista de la ópera se deja llevar por su pasión bastante más que la cervantina. En la pieza de Balfe, el gitanismo no pasa de marco conductual, de un fondo decorativo y flamenco, ya que apenas se refieren sus hábitos. Además, parte de la supuesta irreverencia de la novela residía en que Preciosa, a pesar de sentirse gitana y de adoptar sus costumbres -sus bailes difícilmente se considerarían aceptables en una dama-, resultaba tan virtuosa y discreta como cualquier hija de aristócrata.

32 En opinión de Clamurro $(1997,37)$, “Preciosa's docility is as marked a change as is the uncharacteristic immobility of the gypsies" y el final es "more darkly ironic and conservative than the initial gestures of female autonomy, dramatized in the opening scenes, would suggest" $(40)$. Johnson $(1996,47)$ adelantó que "al ser restituida al lugar que de veras le corresponde en la sociedad, Preciosa [...] se incorpora al orden patricéntrico". Alcalde (129) no se muestra tan pesimista: Preciosa no habría callado solo por obediencia a sus progenitores, sino "para facilitarle a Constanza la incorporación a la nobleza. La única manera en que puede formar parte de la sociedad a la que quiere pertenecer es cediendo a los mecanismos que esta [...] exige". Por eso Boyd $(2013,14)$ arguyó que "es precisamente la seguridad de su autoposesión lo que le permite hacer el papel de la hija sumisa ante sus padres". Y Díez $(2013,76)$ fue un poco más allá: el silencio de Preciosa no resulta significativo, ya que "la poética de la novela exige un final emocionante y rápido y los personajes pierden la palabra, hombres y mujeres, en función de los objetivos globales de la narración en la que se insertan". 
Mi corolario no invalida que Cervantes también vertió un jarro de agua fría sobre la Arcadia calé descrita por el viejo gitano al principio de su novela: alude a la misoginia de sus leyes, ante las cuales Preciosa de nuevo se rebela. Cuando el anciano, sin su consentimiento, se la entrega a Andrés por esposa, ella objeta:

Puesto que estos señores legisladores han hallado por sus leyes que soy tuya, y que por tuya te me han entregado, yo he hallado por la ley de mi voluntad, que es la más fuerte de todas, que no quiero serlo si no es con las condiciones que antes que aquí vinieses entre los dos concertamos. [...] Estos señores bien pueden entregarte mi cuerpo; pero no mi alma, que es libre y nació libre, y ha de ser libre en tanto que yo quisiere. [...] Que yo no me rijo por la bárbara e insolente licencia que estos mis parientes se han tomado de dejar las mujeres, o castigarlas, cuando se les antoja; $\mathrm{y}$, como yo no pienso hacer cosa que llame al castigo, no quiero tomar compañía que por su gusto me deseche. (Cervantes, 1996, 78-79)

El complutense señalaba los puntos débiles de una nobleza corrupta, pero sin ocultar las sombras de los gitanos; por eso, "both court and country life in La Gitanilla represent essentially problematical worlds where neither virtue, vice, nor truth are wholly absolute" (Gerli, 1986, 37).

En la ópera, por el contrario, la única señal de las prácticas romaníes la cantan ellos mismos durante su primera aparición:

In the gipsy's life you read

the life that all would like to lead.

Sometimes under roof, and sometimes thrown

where the wild wolf makes his lair,

for he who's no home to call his own,

will find a home somewhere, ah? Ah?

Tis the maxim bold of man, what's another prize to claim then to keep all he can. 
we gipsies do the same;

thus a habit once, 'tis custom grown,

ev'ry man will take care,

if he has no home to call his own,

to find a home somewhere, ah! Ah! (Bunn, 2017, 80)

Más allá del ambiguo guiño al hurto, se pinta aquí un cuadro estilizado de su nomadismo y libertad. Esta es la causa de que los dos primeros versos del coro ("In the gipsy life you read / the life that all would like to lead") se repitan a menudo a lo largo de la ópera, como un estribillo que remite a los gitanos de los europeos de mediados del Ochocientos. No sorprenderá, entonces, que, solo unos años después del estreno de The Bohemian Girl, "the 'gipsy brat' Heathcliff fell in love with Catherine Earnshaw in Emily Brontë's most acclaimed novel Wuthering Heights [1847], [...] a disgruntled Maggie Tulliver ran off to live with the Gypsies in George Eliot's The Mill on the Floss [1860] and John Crawford Wilson's popular three-act melodrama La Gitanilla or Children of Zincali [1860] opened in London" (Charnon Deutsch, 2004, 112).

Con La gitanilla, Cervantes dibujaba "la más cautivadora y lograda de sus creaciones femeninas" (Avalle-Arce, 1982, 21), mientras que la Arline de Bunn es casi un personaje secundario en el que, de vez en cuando, suenan ecos de la indómita cíngara española; de hecho, su aduar no es más que un espacio encantado que da color a un idilio del todo manido. Por eso, quizá, hoy nadie lo recuerda.

\section{Del libreto al guion: The Bohemian Girl (1936)}

Fruto del éxito de la ópera, The Bohemian Girl llegó pronto a la gran pantalla. Harley Knoles rodaría en 1922 un largometraje mudo homónimo del que solo se conservan cuarenta minutos. Protagonizado por Gladys Cooper (Arline) e Ivor Novello (Thaddeus), fue el primer trabajo como asistente de dirección del maestro Josef von Sternberg (1894-1969), luego nominado al Óscar a Mejor Director en dos ocasiones (Marruecos, 1931; El 
expreso de Shanghái, 1932) ${ }^{33}$. Tristemente, este filme resultó todo un fracaso. Sin duda porque el cine silente no era el mejor destino para una obra que, en esencia, había triunfado gracias a su música. Por lo demás, en 1927 y con idéntico título, Harry B. Parkinson rodaría un corto con Pauline Johnson y Herbert Langley en los papeles principales: también se ha perdido y apenas tenemos noticias ${ }^{34}$.

Otro cantar es la versión de 1936, que ha llegado hasta nuestros días gracias a la fama de los conocidos como el Gordo y el Flaco. La cinta, producida por Hal Roach -responsable de unir a esta pareja en lucrativo matrimonio cinematográfico-, contaba además con sonido, lo cual representó todo un reclamo para atraer a una audiencia que tarareaba las partituras de Balfe. $Y$ si además de deleitar sus oídos, podían pasar un buen rato, el éxito estaba asegurado. Sin esfumar en ningún caso la centra-

33 "Yo pasaba de vez en cuando [por la World Film Corporation] a comprobar la calidad de [los trabajos] de laboratorio, aunque generalmente me daban igual las tonterías que aparecían en la pantalla. Sin embargo, ese día el realizador Harley Knowles [sic] se dirigió a mí para preguntarme mi opinión sobre su película. A mí nunca me la había pedido nadie y no sabía qué contestarle; además, no había estado atento a la que acababan de exhibir. Estaba visiblemente turbado y, como tenía que decir algo, en lugar de alabar la película, dije: «No me gusta la palabra adirondacks en uno de los subtítulos». El realizador me miró perplejo y con voz aguda me preguntó mis razones para pensar eso. Con la naturalidad que logré fingir le contesté: “¿Por qué no usa el término montañas? Nadie sabe dónde se encuentran los adirondacks". Él era inglés y estoy seguro de que tenía tan poca idea de la geografía americana como yo. Me dijo que pensaría mi propuesta. Respiré y salí de allí lo antes posible. A la semana siguiente, un hombre de dudoso aspecto, con la chaqueta llena de ceniza, se me acercó presentándose: William A. Brady. «¿Así que es usted a quien no le gusta la palabra adirondacks?». Pensé que me iba a despedir, pues era el director de la compañía, el dueño de la empresa y el director de sus propias obras en su propio teatro. Grace George era su esposa, y Alice Brady, la famosa actriz de cine, su hija. Saqué fuerzas de donde no las tenía y le confesé que, en efecto, yo era aquel joven. Lejos de mandarme en dirección a la puerta, este ser supremo me comunicó: “Voy a proponerle una cosa. Mis realizadores se dedican a hacer el vago durante semanas, cuando tendrían que estar haciendo películas. Ocúpese de los trabajos de montaje y de edición, coteje la redacción de los subtítulos y, si lo soluciona, puede ganar todo el dinero del mundo" (Von Sternberg, 2002, 164-165).

34 https://www.imdb.com/title/tt0408587/?ref_=nm_flmg_act_13 (visitado el 14 de marzo de 2021). 
lidad del humor. No en vano, la película se estrenaría como "A Comedy Versión of The Bohemian Girl opera by Balfe" (Fig. 1). Recuérdese sobre este particular que, hacia 1936, Stan y Ollie estaban en la cima de su carrera y que tanto Roach como sus guionistas conocían bien las expectativas de los aficionados. De ahí que esta adaptación se defina por dos tramas paralelas: una para los que sentían cierta nostalgia de la ópera inglesa; otra para los que acudían a los cines resueltos a desternillarse con una catarata de gags.

Se trata, pues, de un producto híbrido, cuyo doble argumento cristaliza en un discurso bifronte: un nivel ficcional sirve como el reverso cómico del otro. Por una parte, la "vida romantizada" de los gitanos y el drama del conde Arnheim; y en paralelo, las aventuras de Stan y Ollie: la primera se recrea en los temas del libreto de Bunn y la segunda en las gracietas de los cómicos. El grupo de personajes más operísticos -por así decirlo- se estilizan aquí en aras del placer visual; los otros, en cambio, se pliegan a la jocosidad. Por fin, mientras que la trama de Arline ambiciona la implicación emocional del espectador, la de Laurel y Hardy solo pretende divertirlo.

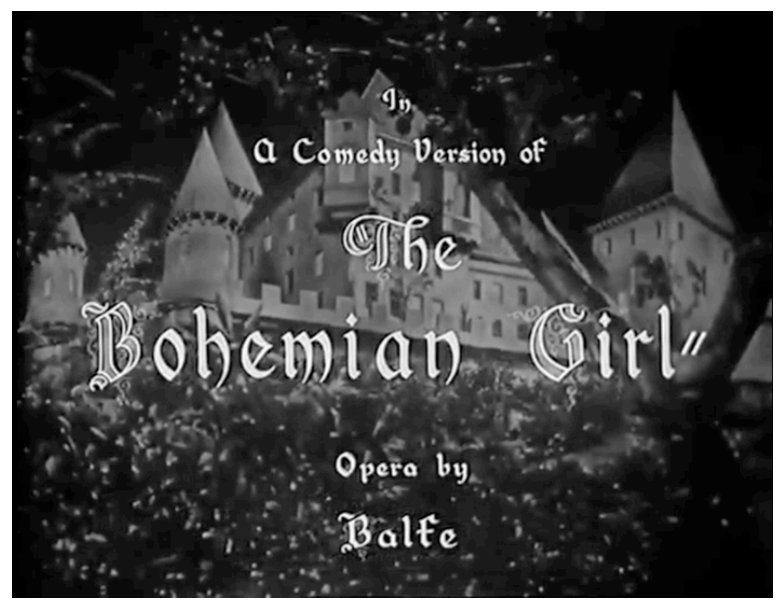

Figura 1 
Ambas realidades se darán la mano en el rapto de Arline, pero en ningún momento se divorcian por completo. Para decirlo de una vez, el protagonismo del Gordo y el Flaco tendrá consecuencias en los amoríos de la joven cíngara. Para empezar, se hizo necesario borrar del mapa a Thaddeus. Paradójicamente -y aunque dudamos de que los guionistas eligieran como piedra de toque La gitanilla de Cervantes ${ }^{35}$-, gracias a dicha elipsis la película -reescritura de otra reescritura- se acerca más al original -esto es, a la primera de las Novelas ejemplares- que la propia ópera. Por su parte, Oliver (el Gordo) colmará el vacío dejado por el fugitivo polaco, ya que criará a Arline tal y como la vieja gitana hiciera con Preciosa.

También desaparece el conflicto amoroso con la reina del aduar. Dado que la Arline cinematográfica carece de pretendientes, el personaje de su adversaria se tornó aquí superfluo. Pero no por ello la cinta anda falta de villanos: la mujer de Ollie (Mae Busch) -de nombre ignoto- urdirá el secuestro de Arline (Darla Hood), deviniendo así en la mayor antagonista de una comedia musical que, por lo demás, se recrea más en las payasadas de los cómicos que en la historia de la niña. Si en la ópera el protagonismo de la gitana menguaba para centrarse en Thaddeus, Arline casi se reduce ahora a un hermoso "MacGuffin"36, acer-

$35 \mathrm{El}$ corte final no presenta créditos de guion, pero debió de tratarse de una escritura a catorce manos: aparte de los directores y del propio Stan Laurel, trabajaron en él James Parrott, Carl Harbaugh, John Guedel y Charlie Hall. De todos ellos, Butler (Oxford, 1890 - 1967) fue sin duda el más popular. Ya había escrito para el dúo cómico un corto antes de las talkies y un par de largos tras la irrupción del sonoro: Sailors, Beware! (Fred Giol y Hal Roach, 1927), Había una vez dos heroes (March of the Wooden Soldiers, Gus Meins y Charley Rogers, 1934) y Dos fusileros sin bala (Bonnie Scotland, James W. Horne, 1935). The Bohemian Girl sería, de hecho, su última colaboración (https://www.imdb.com/name/nm0124918/, visitado el 1 de marzo de 2021). Butler se hizo cargo de 64 guiones y se llevaría el Oscar en 1944 por Siguiendo mi camino (Going My Way), dirigida por Leo McCarey.

36 En palabras de Hitchcock (Truffaut, 2014, 140-141), un MacGuffin "es un rodeo, un truco, una complicidad, lo que se llama un «gimmick». [...] En realidad, esto no tiene importancia y los lógicos se equivocan al buscar la verdad del «MacGuffin»". Por otro lado, Garin $(2014,78)$ subraya la estrecha relación entre el gag visual y el "MacGuffin": "porque al final no importa si un pájaro se come a un gusano o 
cando la película a lo que Crafton bautizó como "gag-driven cinema" ${ }^{37}$.

Como señalé al inicio, la prematura muerte de Thelma Thodd provocó que su papel como reina de los gitanos recayera sobre la veterana Zeffie Tilbury. En un primer momento, la jerarca iba a ser la amante de Devilshoof (Antonio Moreno) -aquí nada más que un apuesto bandolero-, pero Tilbury resultaba demasiado mayor como para protagonizar un affair con el galán, lo cual forzó a los guionistas a traspasar dicha función a la señora de Ollie. La huraña esposa del Gordo cumple a rajatabla con el estereotipo de la mujer tirana y despiadada. Nada nuevo, por otro lado, en los filmes de Laurel y Hardy:

The childlike spirit of their characters, exploited and abused by the world outside the home, is also exploited and abused inside the home: their harridan wives control them like gaolers, give them pocket money, refuse to "allow" them to go out, hit them with plates, frying pans, gramophone records, and their fists. Feminist critics have pointed to the misogyny of the portrayal of women in their films - but in truth the dominance of their women over them and their inability to function in the adult world of "the household" is simply the writers and performers being absolutely truthful to the characters. The theatrical matriarchies that are the Laurel and Hardy homes are natural consequences of their inner story, not fake constructs imposed from without. (Dutton, 2015, 32)

un gato a un pájaro, si un cazador a un elefante o una mujer a un cazador: la imagen que los sustenta a todos es un plano vacío y relativista, una excusa".

37 "Generally, there is a simple plot which frames the gags, with an opening premise and closing scene which provides a resolution. The gags may or may not be thematically related. Wether this is a narrative depends on how insistently one defines it. I argue that despite a weakly structured set of causes and effects, many of these films remain, at best, quasinarratives. Although the shorts emulate feature film narrative structures, the audience is scarcely aware of it, navigating the film from laugh to laugh as though enjoying a sketch" (Crafton, 1994, 109). 
Mrs. Hardy se ceba con su marido, le prohíbe que le dirija la palabra y ni siquiera se esconde al abrazar a su amante. A su vez, raptará a la niña luego de que el conde ordene el castigo de Devilshoof y expulse a los gitanos de la ciudad. Queda, pues, bastante claro que el aristócrata y el pueblo romaní se profesan una antipatía mutua. Entonces, si en la ópera Arnheim tenía por enemigos a los desleales al Imperio, ahora su aversión se ciñe a los faranduleros. Se borra así de un plumazo el telón histórico que personificaba Thaddeus y que, por su gravedad, carecería de sentido dentro de una comedia.

Después de hacerse con la niña y disfrazarla de gitana, la mujer huye con Devilshoof, despojando a los protagonistas de todas sus riquezas y dejándolos al cuidado de la pequeña. Esta tarea, sin embargo, representará un placer para el Gordo, que se derrite con las muecas de una Arline que gesticula al más puro estilo de Shirley Temple (Fig. 2).

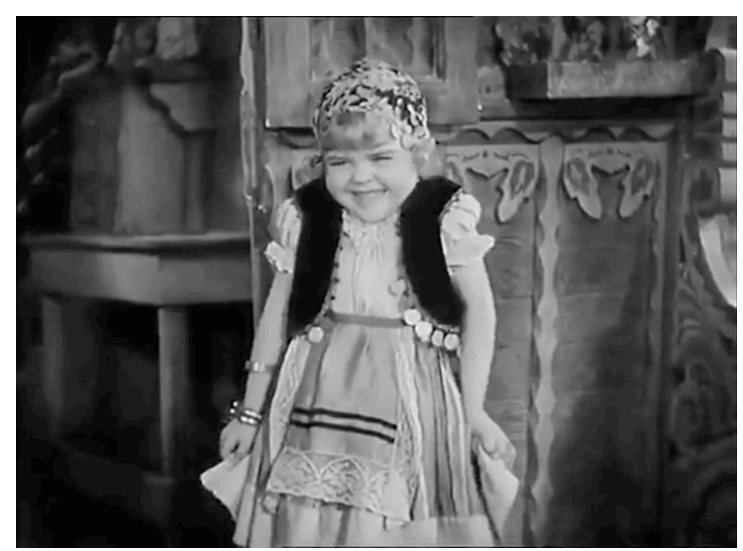

Figura 2

Ollie tampoco pondrá en duda su paternidad biológica tras escucharla de labios de su mujer; a pesar de que cuando la conoce no es precisamente un bebé: 
Oliver. Whose kid is that?

Mrs. Hardy. It's none of your business.

Oliver. What do you mean it is none of my business? I demand to know who she is!

Mrs. Hardy. Well, if you must know, she is yours.

Oliver. Mine? Darling, why didn't you tell me before?

Mrs. Hardy. Because I didn't want her to know who her father was 'til she was old enough to stand the shock. (31:10)

Doce años después, Arline se convierte en una hermosa joven $\left(\right.$ Julie Bishop $^{38}$ ) que cuida de su padre y de su tío Stanley. Mientras los tres desayunan, les cuenta que ha soñado que vivía en un palacio; la mejor excusa para la celebérrima I Dreamt I Dwelt in Marble Halls. A falta de Thaddeus, ahora será Ollie el destinatario de aquel estribillo que rezaba "but I also dreamt, which charm'd the most, that you loved me still the same" (Fig. 3). A continuación, el padre la mira embelesado, mientras que Laurel, ajeno a sus encantos, aprovechará para comerse el plato de su amigo (Figura 4).

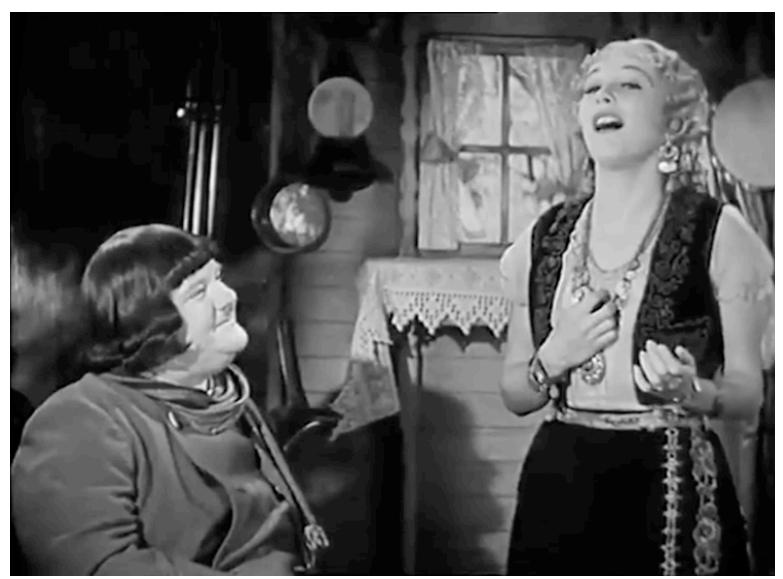

Figura 3

38 En los créditos figura su nombre real, Jacqueline Wells. No se la conocería como Julie Bishop hasta que firmara un contrato con Warner Bros en 1941 (https:// www.imdb.com/name/nm0084098/, visitado el 18 de marzo de 2021). 


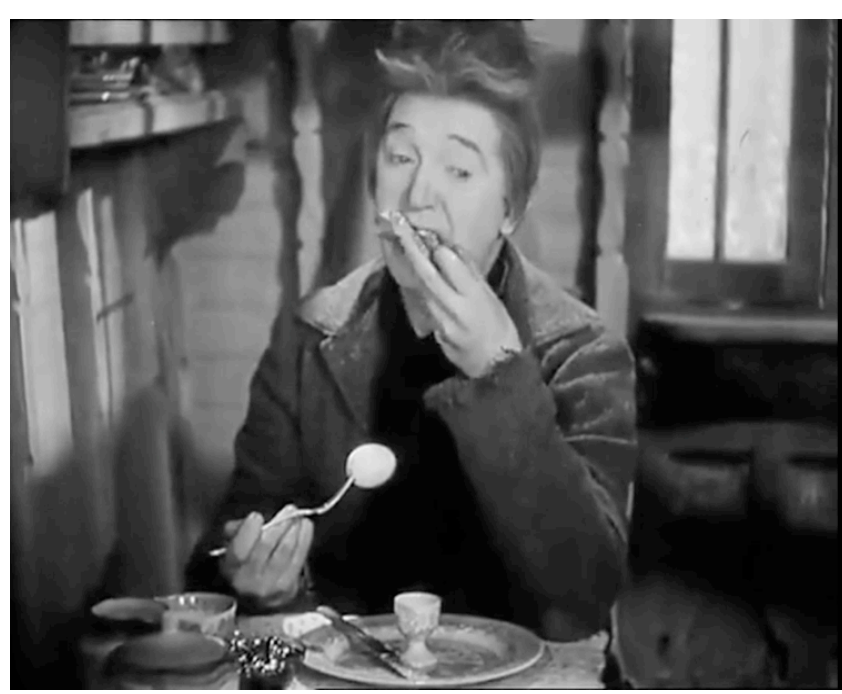

Figura 4

Esta escena es una muestra canónica de la hibridez del largometraje, en tanto que imbrica los dos estilos que la constituyen: el aria de Arline apela al romanticismo y seduce a los fanáticos de la ópera; la glotonería de Stan los lleva de vuelta a la realidad y desencadena sus carcajadas.

Concluida la canción, Arline comunica que debe hacer unos recados en el pueblo. De camino, pasará por el castillo de su padre, lo que propicia el encuentro entre ambos. Huelga abundar en que tampoco Florestein asomará por este filme, aunque la anagnórisis se traduzca en un arresto y en el símbolo del medallón: Arline merodea por los alrededores del bastión paterno y escucha la nostálgica melodía del conde (William P. Carleton), cuyo piano despierta en ella viejos recuerdos. Al sorprenderla husmeando en el jardín, los centinelas de Arnheim la toman presa y, sin verla siquiera, el conde ordena que la flagelen. Uno de los guardias arrancará del cuello de la joven un colgante que después arrojará al suelo: el noble se da cuenta de que era aquel que le regaló a su hija antes de su desaparición, ordena que cese 
el escarmiento y, al contemplar de cerca su espalda desnuda, repara en una marca de nacimiento que corrobora sus sospechas (Fig. 5).

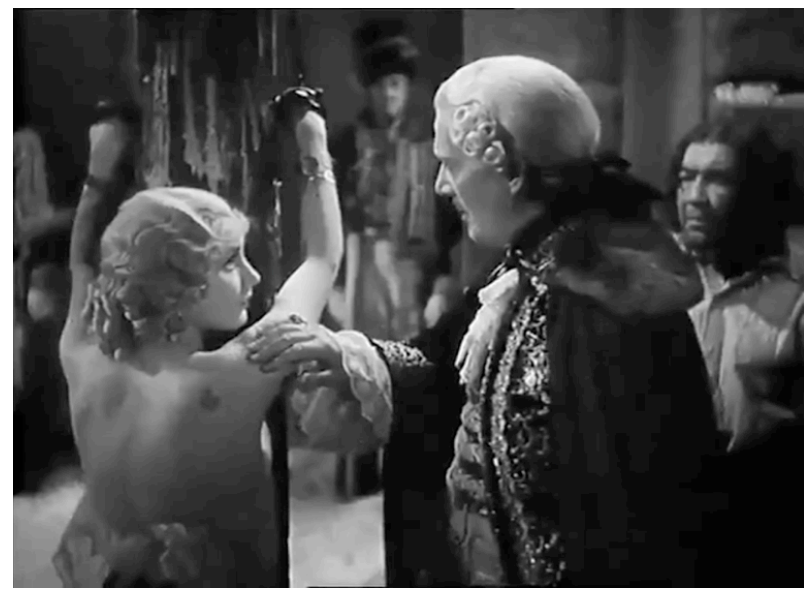

Figura 5

Nótese que si la Arline de Bunn era identificada por una cicatriz, recuerdo del ataque del ciervo, a Preciosa se la reconocía por dos marcas físicas (el lunar bajo el pecho izquierdo y la sindactilia del pie derecho) más un par de "brincos" que la niña lucía antes del secuestro. Sin embargo, en la cinta de Horne y Rogers la anagnórisis linda con la de la novela de Cervantes, quien había usado ya el recurso del collar en la octava de sus Ejemplares: $L a$ ilustre fregona ${ }^{39}$.

Una vez aclarada la peripecia fílmica de Arline, toca ocuparse del "bastidor romaní", a la postre el último residuo de La gitanilla. Los primeros planos de esta libérrima adaptación se concen-

39 Constanza, a fin de cuentas el fruto de una violación, quedó a cargo de los dueños del Mesón del Sevillano, quienes prometieron devolvérsela a su padre llegada la hora. Para no revelar la identidad del susodicho, la madre entregó al ventero "una cadena de oro, que hasta agora tengo, de la cual quitó seis trozos, los cuales dijo que trairía la persona que por la niña viniese" (Cervantes, 1997, 79). 
tran sobre una caravana de jubilosos cíngaros que se asientan en los alrededores del castillo de Arnheim. Solo ahora se los idealiza de forma tan romántica como pintoresca, pues el deambular de Stan y Ollie tiene poco de utópico. Dicha secuencia entronca con la única escena de Thelma Thodd salvada en la sala de montaje (Fig. 6): la intérprete entona -eso sí, doblada-Heart of the Gipsy, un tema original de Nathaniel Shikret y Robert Shayon ${ }^{40}$.

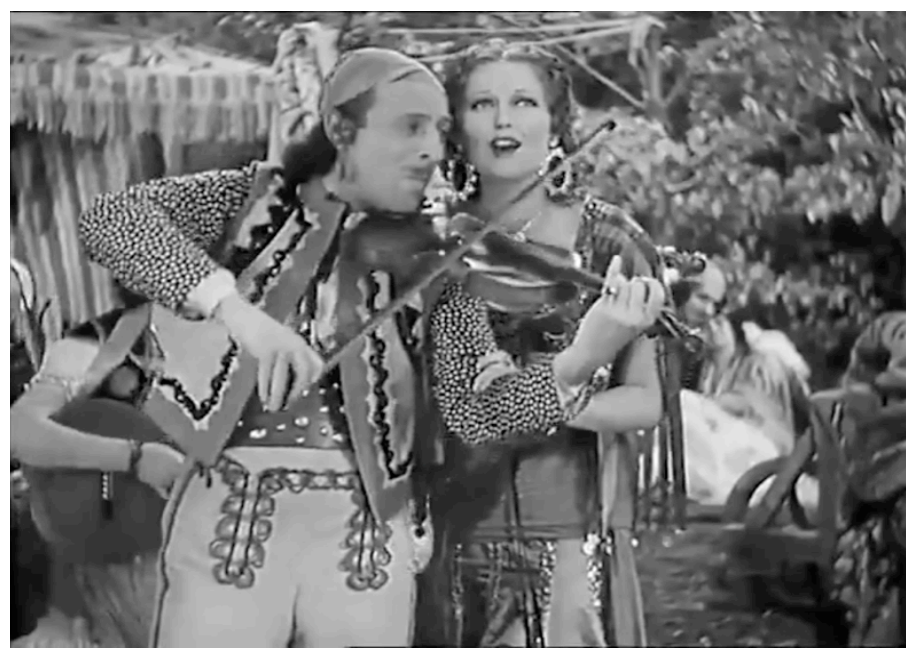

Figura 6

Aunque la ópera sirve de base a la película de los Estudios Roach -también conocidos como "The Lot of Fun"-, sus arias, coros y recitativos no tienen la importancia que cabría esperar. De hecho, Heart of the Gipsy no es la única canción original y solo dos arias proceden por entero del libreto: la de los sueños de Arline (I Dreamt I Dwelt in Marble Halls); y la del adiós de

40 "A Roach le inquietaba más el impacto de la publicidad negativa, alimentada por un tremendo interés de la prensa, con los sabrosos rumores de suicidio o asesinato y revelaciones sobre asuntos y relaciones sentimentales de Thelma [...]. La mayor parte de escenas de Thelma en la película se cortaron y tan solo dejaron una canción doblada" (Louvish, 2003, 326). 
Thaddeus y su amada durante el tercer acto (When Other Lips and Other Hearts), en la que el polaco le ruega que lo recuerde cuando esté con otros hombres:

When other lips and other hearts their tales of love shall tell, in language whose excess imparts the pow'r the feel so well: there may, perhaps, in such a scene some recollection be of days that have as happy been, and you'll remember me. (Bunn, 2017, 144)

En este caso, la letra sirve para que Devilshoof le confiese a la mujer de Ollie que, al no poseer hacienda, no podrá llevarla consigo en su huida -una estratagema para que ella se haga con las joyas de su marido-: por consiguiente, la fuga se antoja más bien una despedida. Asimismo, un par de versos de la ópera se incorporan a las nuevas composiciones: los recurrentes "In the gipsy's life you read / the life that all would like to lead" -elogio de la vida gitana- y el lamento del conde Arnheim por su hija desaparecida ("But mem'ry is the only friend / that grief can call its own").

Y frente a la hidalguía y la bohemia, de espaldas a los cantos melancólicos o festivos, Stan y Oliver se afanan en la pedestre tarea de mondar patatas (Fig. 7). Nada queda ya del ensueño en el que nos sumergieron los primeros planos: la rutina de este par de gitanos es tan apático e insulso como el de cualquier otro sujeto. Fijémonos además en otro detalle: el locus amoenus del inicio se reduce a una caravana destartalada, una hoguera y una cuerda en la que se seca la ropa.

Primero el Flaco pela una patata y la arroja a la olla, salpicando a su compañero. La escena no tarda en repetirse. Molesto, Ollie tira otra con fuerza para vengarse de su amigo, con tan mala fortuna que rebota primero en el borde de la cacerola y des- 
pués contra su nariz ${ }^{41}$. Los directores bosquejan así el papel de cada uno de ellos: "en un cambio de la relación normal entre Stan y Ollie, Stan es el ladrón competente y Ollie el burro" (Louvish, $2003,327)^{42}$. Y claro, también la música cambia súbitamente para transportarnos del mundo de la ópera al del slapstick.

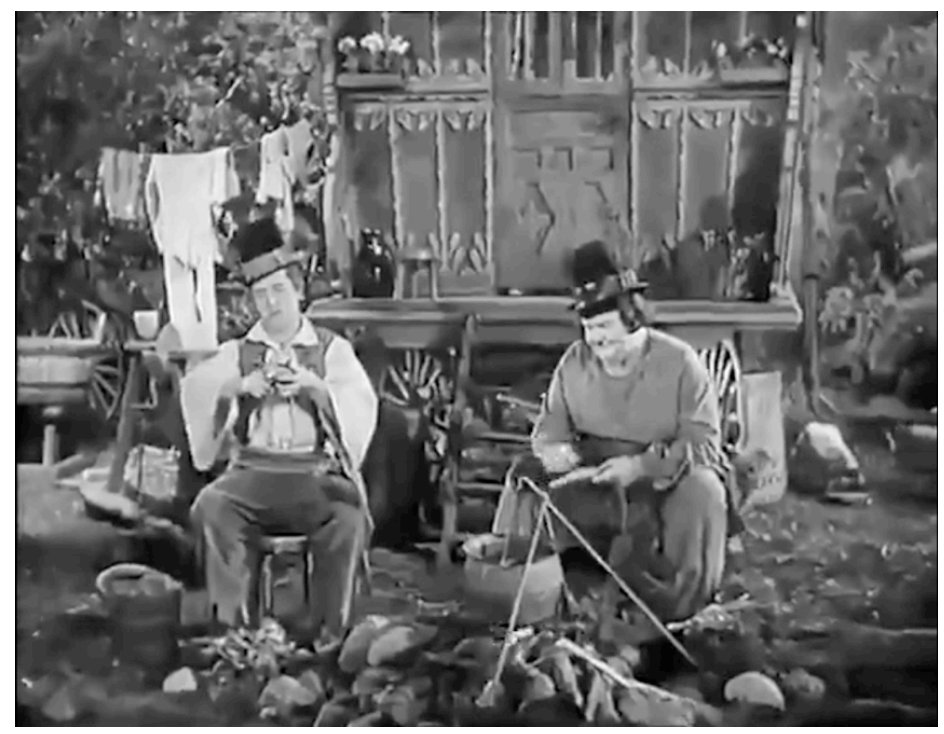

Figura 7

Sus aventuras nunca se desvían de este tipo de chistes, herederos del cine mudo, que también permean sus tres hurtos: un

41 Este gag sigue la perfecta estructura en tres pasos construida a través del tiempo (Garin, 2014, 25): 1) la espera (Stan moja a Ollie dos veces), 2) la anticipación (prevemos la venganza de Ollie contra Stan), 3) la sorpresa (Ollie acaba golpeándose a sí mismo).

42 Garin $(2014,254)$ puntualiza que "la grandeza de Laurel \& Hardy está en que no solo intercambian papeles como eiron [personaje activo-jactancioso] y alazon [reactivo-irónico], sino que son capaces de hacerlo con una especie de rotundidad ambivalente, una contradicción en términos que los viste de bomolochoi [expansivo-abierto] y agroikos [retraído-seco] a ratos, según patrones de comportamientos puramente visuales". 
borracho les pide que le digan la buenaventura. Laurel accede. Le ordena que cierre los ojos y controla que no haga trampas apoyando dos dedos sobre sus párpados. Mientras fabula un futuro para su víctima, le va sisando tanto las alhajas como el dinero. Y aunque Ollie intenta imitarlo poco después, su pericia como estafador no admite comparación con la de Stan, hasta el punto de ser descubierto por una nueva víctima (Fig. 8), que, lejos de caer en la trampa, observa molesto el robo mientras los ladronzuelos gozan de su nuevo botín ${ }^{43}$. La rapiña se dilata durante un par de minutos, los cuales constituyen una perfecta muestra del slow burn, un tipo de gag que se originó, justamente, en los filmes de Laurel y Hardy: "se trata de una dilatación progresiva del gesto que cocina el gag a fuego lento, segundo a segundo, sacando el máximo partido de la paciencia -y la capacidad de aguantar- de los actores" (Garin, 2014, 57-58). Su paternidad se atribuye a Edgar Kennedy, quien exprimió el slow burn en el gag de la limonada de Sopa de ganso (Duck Soup, Leo McCarey, 1933). McCarey lo empleó con frecuencia en las películas del Gordo y el Flaco. Un ejemplo ya clásico es la escena de la tarta y el tropezón de Ollie en el corto From Soup to Nuts (Edgar Kennedy, 1928), donde "llama la atención esa insistencia en que el actor no haga nada, es decir, que actúe sin actuar, manteniéndose impasible" (Garin, 2014, 59).

43 He aquí la primera de una serie de escenas caracterizables como running gag; es decir, un gag recurrente: el del burlador que no advierte que el burlado es del todo consciente de la befa. Aflora durante el robo de Ollie; después, cuando Stan intenta robar las joyas escondidas debajo del colchón de su amigo; y, una vez más, en el intento de sacar a Arline del calabozo de su padre, para lo que toman las llaves del bolsillo del guardia. 


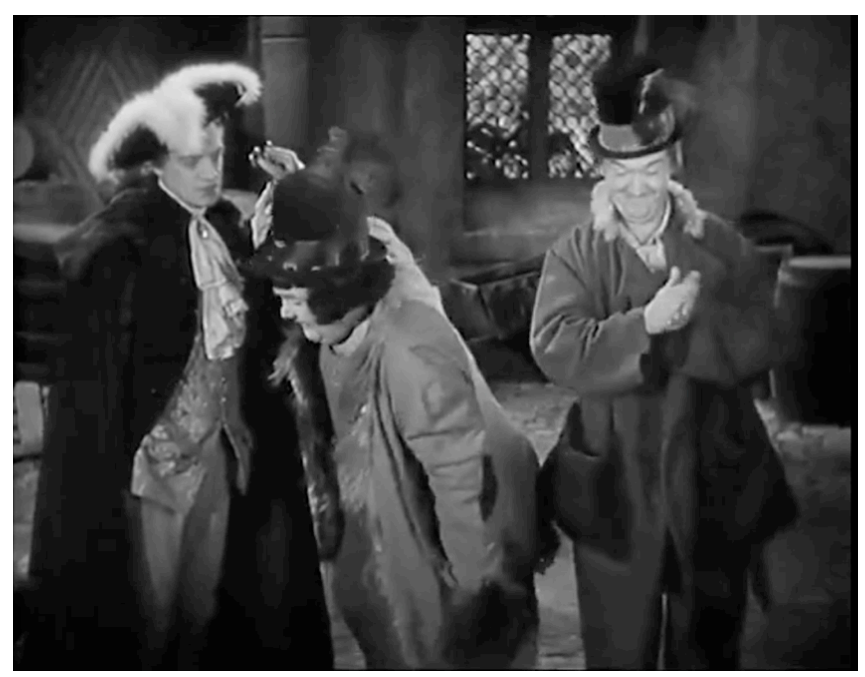

Figura 8

Pero no los reduzcamos a la risa: en estos lances, aunque transformados por el aliento cómico de sus protagonistas, se acentúan dos atributos de los gitanos, también aludidos en $L a$ gitanilla y -aunque menos connotados- en la ópera de Balfe: la adivinación y el robo. El segundo de ellos, para qué negarlo, convierte al Gordo y el Flaco en una suerte de Rinconete y Cortadillo de andar por casa.

Llama la atención que Laurel y Hardy jamás aparezcan junto a los gitanos músicos y danzarines. Dentro del campamento, únicamente los veremos con la mujer del Gordo y con Devilshoof. Este "cisma" no parece casual en absoluto: los primeros pertenecen a la misma esfera romántica que Arline y el conde Arnheim; los otros encarnan el desengaño de esa vida tan afectada como utópica, enseguida llevada al límite contrario desde el humor surrealista: de ahí que sean vilipendiados y zaheridos de principio a fin. Luego, casi por casualidad, el filme hereda más del alma de La gitanilla de Cervantes que el libreto de 1843. Mientras que Bunn dio al traste con el "ideorrealismo cervanti- 
no" (Mata Induráin, 2010, 21), el filme de Rogers y Horne vuelve a unir ambos planos. Empero, si la faceta más salvaje y proscrita de los gitanos de la primera de las Ejemplares se reducía a su misoginia, los cinematográficos sufren por las malas artes de la mujer de Ollie, trasunto de aquella "reina" operística. Además, la "guerra de los sexos" no responde tan solo a los estilemas del Gordo y el Flaco, sino que le debe lo suyo a otro efecto cómico: a este par de gitanos no les faltan oportunidades para repartirse las tareas domésticas, como si de un verdadero matrimonio se tratara (Fig. 9); lo cual, a buen seguro, despertaría la risa de los espectadores de los años treinta.

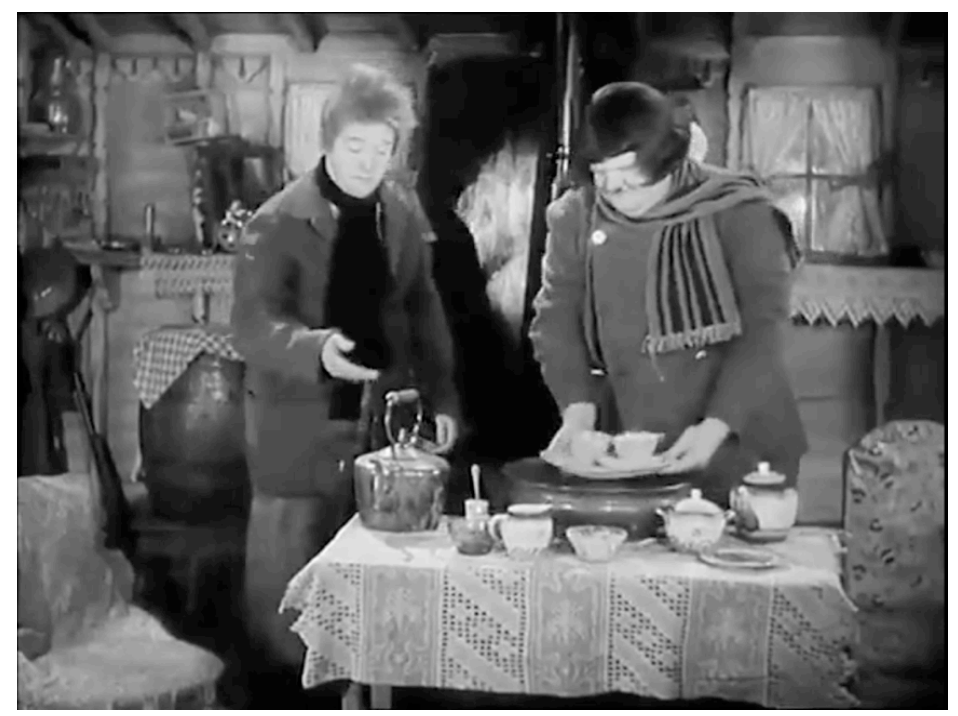

Figura 9

En definitiva, La gitanilla de Cervantes sentó las bases de una tradición que, a caballo entre varias artes, viajaría en el espacio y en el tiempo con resultados de lo más dispares; por ejemplo, el libreto de Alfred Bunn y la película protagonizada por Stan Laurel y Oliver Hardy. The Bohemian Girl arranca de la novela barroca, pero la combina -y la esfuma- con otros ejercicios (re) 
creativos. El romanticismo decimonónico, vindicador de marginales, floreció en los cíngaros de Balfe, dando al traste con el incisivo "realismo" cervantino. Diríase, pues, que aquí el gitanismo aparece más como la tramoya de un melodrama al uso que como el núcleo de la acción.

Un par de gitanos aprovechó el éxito de la ópera, aún vigente durante los años treinta, para presentar una historia de gran popularidad en clave de slapstick. El resultado es una comedia híbrida en la que se dan la mano la idealización y el humor patético. La película de Rogers y Horne se hace eco de la poetización de los gitanos que se forjó en la Europa de los siglos XVIII y XIX, pero, al mismo tiempo, nos devuelve a la realidad mundana a través de la pareja protagonista. La Arcadia queda lejos de estos simpáticos truhanes -maltratados al principio por Mrs. Hardy, torturados después por los guardias del conde- que se desviven por sacarle una sonrisa al espectador.

No obstante, si en la Arline operística apenas se apreciaban vestigios de Preciosa, la encarnada por Julie Bishop se halla en sus antípodas: no alterna con los de su clase, no baila ni posee dotes quirománticas; en este caso, carece incluso de la trama amorosa que la mantenía ocupada en el libreto. De ahí que la muchacha no solo pierda su protagonismo, sino que se "desgitanice" por completo. En su lugar, un dúo de "clowns neopícaros" invade el argumento, mostrando el lado más bajo (y divertido) de estos gitanos. Es cierto que, al relegar al personaje femenino a un segundo plano, la película lo desvirtúa; sin embargo, la trabazón de una faceta romántica con otra más prosaica consigue resucitar el espíritu de La gitanilla. Al fin y al cabo, nada hay más barroco que el claroscuro; y pocas cosas más cervantinas que una buena dosis de risa.

\section{OBRAS CITADAS}

Alcalde, P. (1997) "El poder de la palabra y el dinero en $\mathrm{La}$ gitanilla", Cervantes: Bulletin of the Cervantes Society of America, 17$2,122-132$. 
Aranda Arribas, V. (2020) “ «Mi ingenio las engendró y van creciendo en los brazos de la cámara»: la novela corta del Barroco en el cine y la televisión", Janus, 9, 596-642.

Avalle-Arce, J. B. (1982) "Introducción”, en Cervantes, M., Novelas ejemplares I, Madrid, Castalia, 9-37.

"Bohemian Girl to Be Here October 2" (22/09/192), The Bismarck Tribune, 6.

Boyd, S. (2013) "El misterio de la identidad personal en $\mathrm{La}$ gitanilla", Ínsula, 799-800, 11-14.

Bunn, A. (2017) The Bohemian Girl, en Pérez Fernández, J. J. Michael William Balfe y "The Bohemian Girl", Vigo, Academia del Hispanismo, 75-164.

BARR, C. (1974) Laurel \& Hardy, Berkeley, University of California Press.

Cabero, J. A. (1949) Historia de la cinematografía española, Madrid, Gráficas Cinema.

Cabeza San Deogracias, J. (2005) El descanso del guerrero: el cine en Madrid durante la Guerra Civil española (1936-1939), Madrid, Rialp.

Casalduero, J. (1969) Sentido y forma de las "Novelas ejemplares", Madrid, Gredos.

Cervantes, M. (1996) La gitanilla. El amante liberal, Sevilla Arroyo, F. y Rey Hazas, A. (eds.), Madrid, Alianza.

Cervantes, M. (1997) La ilustre fregona. Las dos doncellas. La señora Cornelia, Sevilla Arroyo, F. y Rey Hazas, A. (eds.), Madrid, Alianza.

Charnon-Deutsch, L. (2004) The Spanish Gypsy. The History of a European obsession, Pennsylvania, The Pennsylvania State University Press.

Christmas, E. (18/06/1921) "Singing is a Municipal Project in St. Paul", The Deadborn Independent, 11.

Clamurro, W. H. (1997) Beneath the Fiction. The Contrary Worlds of Cervantes's "Novelas ejemplares", Nueva York, Peter Lang. 
Crafton, D. (1994) "Pie and Chase: Gag, Spectacle and Narrative in Slapstick Comedy", en Brunovska Karnick, K. y Jenkins, H. (eds.), Classical Hollywood Comedy, Nueva York, Routledge, 106-119.

Craine, D. y Mackrell, J. (2010) "La Gypsy”. Oxford Dictionary of Dance, Orford, Oxford University Press.

Dalla Valle, D. (1992) “Novella / tragicomedia: dalla novella spagnola alla tragicomedia francese", en Scarano, E. y Diamanti, D. (eds.), Riscrittura, intertestualità, transcodificazione, Pisa, Tipografia Editrice Pisana, 207-215.

DARnis, P. (2007) “Cervantes y el relato de enigma (I): el Casamiento engañoso en la historia literaria de Occidente", Voz y Letra, 18-1, 49-66.

DARnis, P. (2010) “La «ilustre fregona»: crónica de un desciframiento progresivo (Cervantes y el nacimiento del relato de enigma II)", en Darnis, P. (dir.), Le commencement... en perspective: L'analyse de l'incipit et des cuvres pionnières dans la littérature du Moyen-Âge et $d u$ Siècle d'or, Toulouse, Presses Universitaires du Midi, 83-99.

Darnis, P. (2013) “¿Por qué y cómo son ejemplares las Novelas ejemplares? (I). Una vuelta a los conceptos de mímesis y ética", Artifara, 13 bis, 7-32.

DARnis, P. (2014) "La fuerza de la sangre, La ilustre fregona y Las dos doncellas: ¿tres tipos folclóricos?", Edad de Oro, XXXIII, 151162.

Darnis, P. (2015) “¿Por qué y cómo son ejemplares las Novelas ejemplares? El Licenciado Vidriera, el Celoso extremeño, el Casamiento engañoso y la novella trágica cervantina", en Marigno, E., Mata Induráin, C. y Ramírez Sierra, H. H. (eds.), Cervantes creador y Cervantes recreado, Pamplona, Servicio de Publicaciones de la Universidad de Navarra (BIADIG), 31-61.

Díez, J. I. (2013) “The Rest is Silence: protagonista femenina y final de la novela en La gitanilla y La española inglesa", Cálamo FASPE, 62, 69-76. 
Dutton, J. (2015) Keeping Quiet: Visual Comedy in the Age of Sound, Gosport, Chaplin Books.

Forcione, A. K. (1982) Cervantes and the Humanist Vision: a Study of Four Exemplary Novels, Princeton, Princeton University.

García Fernández, E. C. (2002) El cine español entre 1896 y 1939. Historia, industria, filmografía, documentos, Madrid, Ariel.

García López, J. (2013) "Notas complementarias", en Cervantes, M., Novelas ejemplares, Jorge García López (ed.), Madrid, Real Academia Española / Galaxia Gutenberg, 821-1126.

Garin, M. (2014) El gag visual. De Buster Keaton a Super Mario, Madrid, Cátedra.

Garrido Ardila, J. A. (2009) “The Influence and Reception of Cervantes in Britain (1607-2005)", en Garrido Ardila, J. A. (ed.), The Cervantean Heritage. Reception and Influence of Cervantes in Britain, Londres, Legenda, 2-31.

Gaskell, I. (1982) “Transformations of Cervantes's La gitanilla in Dutch Art", Journal of the Warburg and Courtauld Institutes, 45, 263-270.

Gautier, T. (2008) Viaje por España, Valladolid, Maxtor.

Gerli, E. M. (1986) "Idealism and Irony in La gitanilla", Cervantes: Bulletin of the Cervantes Society of America, 6-1, 29-38.

González, L. M. y Medina, P. (2017) Cervantes en imágenes. Donde se cuenta cómo el cine y la televisión adaptaron su vida y su obra, Alcalá de Henares, Festival de Cine de Alcalá de Henares / Comunidad de Madrid.

Hancock, T. (2002) "UNL to Revive Influential Bohemian Girl”, The Mowers' Tree. The Newsletter of the Cather Colloquium 2: https:// cather.unl.edu/scholarship/mowerstree/wtr02/mt.wtr02.07. Visitada el 21 de marzo de 2021.

IvanovicI, V. (2002) "Preciosa y su prenda tan preciada (Una lectura de La gitanilla)", en Villa Lecumberri, A. (coord.), Cervantes en Italia: Actas del X Coloquio Internacional de la Asociación de Cervantistas: Academia de España, Roma 27-29 septiembre 2001, Palma de Mallorca, Asociación de Cervantistas, 213-227. 
Johnson, C. B. (1996) “De economías y linajes en La gitanilla", Mester, 25-1, 31-48.

Koopman, D. (2008) Cervantes, Cats en de Amsterdamse Schouwburg De geschiedenis van een Spaans Zigeunermeisje: http://www. denniskoopman.nl/pdf/zigeunermeisje.pdf. Visitada el 18 de marzo de 2021.

Looser, D. (2008) Women Writers and Old Age in Great Britain (1750-1850), Baltimore, The John Hopkins University Press.

Louvish, S. (2003) Stan \& Ollie. Las raíces de la comedia: la doble vida de Laurel y Hardy, Goyeneche, I. (trad.), Madrid, T\&B.

Márquez Villanueva, F. (1985) “La buenaventura de Preciosa", Nueva Revista de Filología Hispánica, XXIV, 741-768.

Mata Induráin, C. (2010) "Introducción”, en Cervantes, M., Novelas ejemplares (La gitanilla. Rinconete y Cortadillo), Madrid, Editex.

McLean, T. (2007) “Nobody's Argument: Jane Porter and the Historical Novel", Journal for Early Modern Cultural Studies, 7-2, 88-103.

Monrós-Gaspar, L. (2017) "La gitanilla en el teatro cómico victoriano. Textos y contextos", Anales cervantinos, XLIX, 271-293.

Montero Reguera, J. (2013) "La gitanilla: una reivindicación de la poesía", Ínsula, 799-800, 34-36.

Nieto Jiménez, R. (2012) El cine de Juan de Orduña: actor, director y productor cinematográfico, Madrid, Universidad Autónoma de Madrid.

Pardo García, P. J. (2010) “Teoría y práctica de la reescritura filmoliteraria (A propósito de las reescrituras de The Turn of the Screw)", en Pérez Bowie, J. A. (ed.), Reescrituras fílmicas: nuevos territorios de la adaptación, Salamanca, Ediciones de la Universidad de Salamanca, 45-102.

Pardo García, P. J. (2017) “De la transescritura a la transmedialidad: poética de la ficción transmedia", en Gil González, A. J. y Pardo García, P. J. (eds.), Adaptación 2.0. Estudios comparados sobre intermedialidad, Binges, Orbis Tertius, 41-92. 
Pérez Bowie, J. A. (2010) "Sobre reescritura y nociones conexas: un estado de la cuestión", en Pérez Bowie, J. A. (ed.), Reescrituras fímicas: nuevos territorios de la adaptación, Salamanca, Ediciones de la Universidad de Salamanca, 21-43.

Pérez Fernández, J. J. (2014) “La gitanilla y The Bohemian Girl: la trayectoria musical de un tema cervantino", Diligec: Revista Internacional de Lenguas y Culturas, 1, 42-58.

Pérez Fernández, J. J. (2017) Michael William Balfe y "The Bohemian Girl", Vigo, Academia del Hispanismo.

Piñeiro GiL, E. C. (1994) “The Spanish Student y La gitanilla: del convencionalismo a la rebeldía", REDEN: Revista Española De Estudios Norteamericanos, 8, 81-92.

Rodríguez-Luis, J. (1980) Novedad y ejemplo de las novelas de Cervantes, Madrid, José Porrúa.

Ropars-Wuilleumier, M. C. (1990), Écraniques. Le film du texte, Lille, Presses Universitaires de Lille.

Ropars-Wuilleumier, M. C. (1993) “L'Oubli du texte”, Cinémas, 4-1, 11-22.

Ruız Álvarez, R. (1991) “La transferencia de géneros, modelo de interpretación de otra cultura: A. Hardy", en Lafarga, F. y Donaire Fernández, M. L. (coords.), Traducción y adaptación cultural: España-Francia, Oviedo, Universidad de Oviedo, 243-252.

Seguin, J. C. (2015) “Las Novelas ejemplares en tiempos del cine silente", en Marigno, E., Mata Induráin, C., y Ramírez Sierra, H. H. (eds.), Cervantes creador y Cervantes recreado, Pamplona, Servicio de Publicaciones de la Universidad de Navarra (BIADIG), 249-279.

Serceau, M. (1999) L'adaptation cinémathographique des textes littéraires. Théories et lectures, Lieja, Éditions du Cefal.

Serralta, F. (1987) Antonio de Solís et la "comedia" d'intrigue, Tolouse, Université Toulouse-Le Mirail.

Sevilla Arroyo, F. y Rey Hazas, A. (1996), "Introducción”, en Cervantes, M., La gitanilla. El amante liberal, Madrid, Alianza, I-LXVIII. 
Torres, B. (2018) “La poesía en La gitanilla: ¿Es preciosa «algo desenvuelta, pero no de modo que descubriese algún género de deshonestidad»?", Hesperia. Anuario de Filología Hispánica, XXI-2, 133-150.

Truffaut, F. (2014) El cine según Hitchcock, Madrid, Alianza.

Vaiopoulos, K. (2003) Temi cervantini a Napoli. "La Zingaretta" di Carlo Celano, Florencia, Alinea.

VAiopoulos, K. (2010) De la novela a la comedia: las "Novelas ejemplares" de Cervantes en el teatro del Siglo de Oro, Vigo, Academia del Hispanismo.

Vieu-Kuik, H. J. (1976) “Inleiding”, en Cats, J., Het Spaens heydinnetje, Culemborg, Tjeenk Willink / Noorduijn.

Von Sternberg, J. (2002) Diversión en una lavandería china. Memorias, Sánchez, N. (trad.), Madrid, JC Clementine.

Welkos, R. W. (2002) "A Mystery Revisited A building that figured in the unsolved death of actress Thelma Todd is for sale", Los Angeles Times: https://www.latimes.com/archives/la-xpm2002-may-29-et-welkos29-story.html. Visitado el 21 de marzo de 2021. 